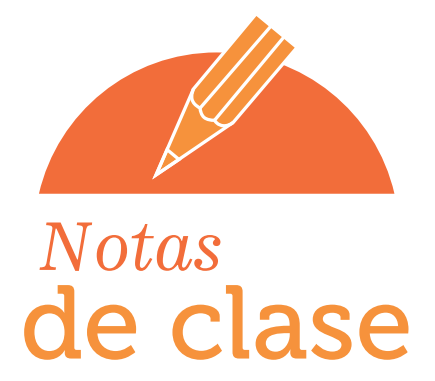

Apropiación social del conocimiento

Generación de contenidos impresos https://repository.ucc.edu.co/handle/20.500.12494/7375

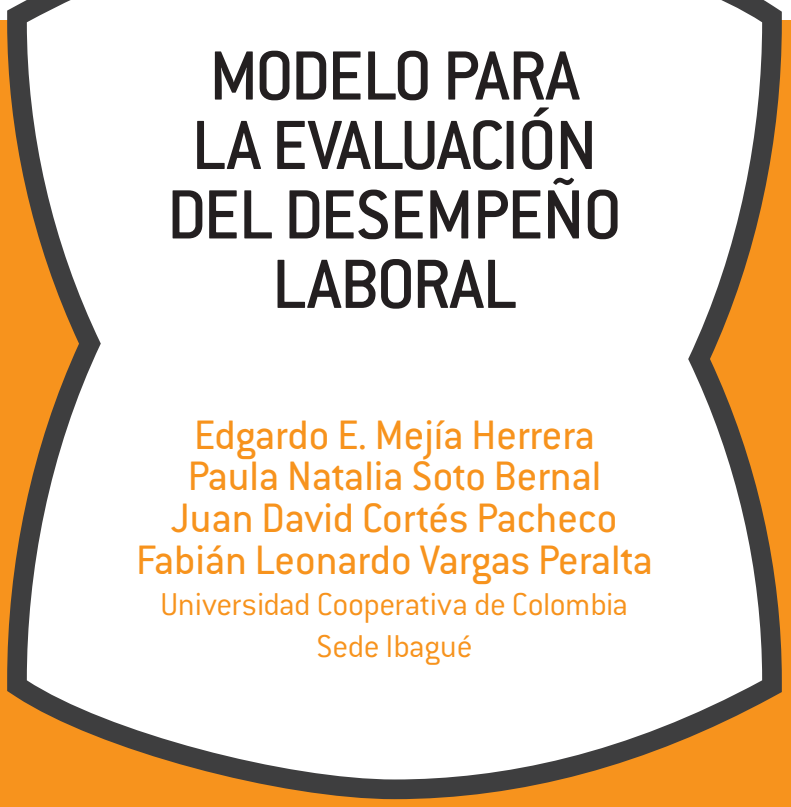




\section{ACERCA DE LOS AUTORES}

Edgardo Mejía-Herrera, candidato a doctor en Administración Gerencial, magíster en Ciencias de la Educación Mención en Docencia e Investigación Universitaria. Profesor auxiliar del programa de Administración de Empresas, Universidad Cooperativa de Colombia, sede Ibagué.

Correo electrónico:

edgardo.mejia@campusucc.edu.co

Cvlac:https://scienti.minciencias.gov.co/ cvlac/visualizador/generarCurriculoCv.do?cod_rh=0000800805

Gruplac:https://scienti.minciencias.gov. co/gruplac/jsp/visualiza/visualizagr.jsp?nro $=00000000005198$

orcid: https://orcid.org/0000-0002-7269-6591

Paula Natalia Soto Bernal, técnico en Administración pymes. Aspirante al título profesional en Administración de Empresas, Universidad Cooperativa de Colombia, sede Ibagué.

Correo electrónico:

natisotoo4@gmail.com
Juan David Cortés Pacheco, aspirante al título profesional en Administración de Empresas, Universidad Cooperativa de Colombia, sede Ibagué. Correo electrónico:

juan.cortespa@campusucc.edu.co

Fabián Leonardo Vargas Peralta, aspirante al título profesional en Administración de Empresas, Universidad Cooperativa de Colombia, sede Ibagué.

Correo electrónico:

fabian.vargaspe@campusucc.edu.co

\section{CÓMO CITAR ESTE DOCUMENTO}

Mejía-Herrera, E., Soto Bernal, P. N., Cortés Pacheco, J. D. y Vargas Peralta, F. L. (2021). Modelo para la evaluación del desempeño laboral (Generación de contenidos impresos $\mathrm{N}^{\circ}{ }^{18}$ ). Ediciones Universidad Cooperativa de Colombia. doi: https://doi.org/10.16925/gcnc.21

NOTA LEGAL

El presente documento de trabajo ha sido incluido dentro de nuestro repositorio institucional como Apropiación social de conocimiento por solicitud del autor, con fines informativos, educativos o académicos. Asimismo, los argumentos, datos y análisis incluidos en el texto son responsabilidad absoluta del autor y no representan la opinión del Fondo Editorial o de la Universidad.

DISCLAIMER

This coursework paper has been uploaded to our institutional repository as Social Appropriation of Knowledge due to the request of the author. This document should be used for informational, educational or academic purposes only. Arguments, data and analysis included in this document represent authors' opinion not the Press or the University.

(c) (1) () $\Theta$ Este documento puede ser consultado, descargado o reproducido desde nuestro repositorio institucional (http://repository.ucc.edu.co/handle/20.500.12494/7369) para uso de sus contenidos, bajo la licencia de Creative Commons Reconocimiento-NoComercial-SinObraDerivada 4.0 Internacional. http://creativecommons.org/licenses/by-nc-nd/4.0/ 


\section{TABLA DE CONTENIDO}

$\begin{array}{ll}\text { INTRODUCCIÓN } & 7\end{array}$

$\begin{array}{ll}\text { PREFAcIO } & 7\end{array}$

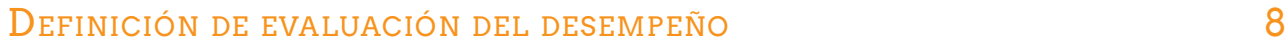

RESPONSABILIDAD DE LA EVALUACIÓN DEL DESEMPEÑO LABORAL 9

¿QUiÉn DEBE EVALUAR EL DESEMPEÑO LABORAL EN EL SECTOR PRIVADO? 9

$\begin{array}{ll}\text { Periodo en el QUe Se desarRollará la eVAluación } & 10\end{array}$

OBJETIVOS DE LA EVALUACIÓN DEL DESEMPEÑO LABORAL 10

$\begin{array}{ll}\text { Proceso Para eVAlUar EL DESEMPeÑo laboral } & 10\end{array}$

Planeación de la eVAluación DeL desempeño 10

Selección del instrumento y método de evaluación 12

Concertación de Objetivos 23

La entrevista de concertación de objetivos $\quad 23$

Estándares objetivos 24

Planeación estratégica $\quad 25$

Análisis y descripción de cargos 25

Compromisos laborales 25

Compromisos comportamentales $\quad 26$

Instructivo para la concertación de objetivos laborales 26

El SEguimiento Al EVALUAdo 26

COMPARACIÓN DE RESUltados VS los OBjetivos CONCERTAdos 28

$\begin{array}{ll}\text { FiJACIÓN DE ACCIONES CORRECTIVAS } & 29\end{array}$ 


\section{LISTA DE FIGURAS}

Figura 1. Responsables de la evaluación del desempeño laboral. 9

Figura 2. Proceso para evaluar el desempeño laboral 11

en empresas privada.

Figura 3. Fases del proceso de evaluación del desempeño 11 en el Estado colombiano.

Figura 4. Evaluación de 360 grados. Elaboración propia.

Tabla 1. Modelo del método de escalas gráficas 13

Tabla 2. Método de escala gráfica con utilización de puntos 14

Tabla 3. Método de elección forzada $\quad 15$

Tabla 4. Método de comparación por pares 15

Tabla 5. Método de incidentes críticos $\quad 17$

Tabla 6. Método de frases descriptivas 17

Tabla 7. Instrumento para evaluar el desempeño 20

en las empresas del sector privado

Tabla 8. Ejemplo cálculo de compromisos laborales 22

Tabla 9. Formato de concertación de objetivos 27

Tabla 10. Formato de registro de evidencias 28

Tabla 11. Niveles de desempeño $\quad 30$ 


\section{MODELO PARA LA EVALUACIÓN}

Edgardo E. Mejía Herrera

Paula Natalia Soto Bernal

Juan David Cortés Pacheco

Fabián Leonardo Vargas Peralta

\section{Resumen}

El propósito del presente trabajo es darle al lector las pautas de cómo evaluar el desempeño laboral en las empresas del sector privado. Con el desarrollo del trabajo se hilarán los pasos para llevar a cabo la evaluación del desempeño laboral, comenzando por su planificación, en la cual se debe escoger el instrumento y el método para evaluar, definir el tiempo en el que se llevará a cabo la evaluación y los responsables de su cumplimiento; se darán las indicaciones de cómo concertar los objetivos y los compromisos por evaluar; el seguimiento que se le debe hacer al evaluado; cómo evaluar los resultados versus los objetivos concertados; se dan las pautas para corregir las desviaciones en los objetivos; cómo se hace la evaluación final y los recursos a los que pueden tener derechos los evaluados en la evaluación final propios de un debido proceso. Es necesario que todo administrador conozca y aplique las herramientas de una evaluación del desempeño, como una de las competencias propias de la gestión de empresas, ya que lo anterior le servirá para encarrilar las metas para su cumplimiento, todo los anterior enfocado hacia los objetivos visionales, misionales y estratégicos de la organización.

Palabras clave: compromisos, desempeño, evaluación, medición, objetivo. 


\section{INTRODUCCIÓN}

La gestión del talento humano abarca el estudio del análisis y la descripción de cargos, la planeación, el reclutamiento y la selección de personal, el desarrollo y la capacitación, la evaluación del desempeño y remuneración de la fuerza de trabajo, el bienestar social y la seguridad e higiene de estos, entre otros aspectos.

En el presente trabajo se abordará uno de los temas anteriormente descritos, ya que se hace referencia a la evaluación del desempeño laboral; con ello se busca que el lector adquiera la competencia de evaluar la fuerza de trabajo en las empresas, para contribuir a la consecución de los objetivos corporativos; la evaluación del desempeño laboral es un proceso que sirve para tomar las medidas correctivas en las ejecuciones de los subordinados y en otros casos recompensar aquellas aptitudes y acciones que se hayan dado por encima de las expectativas esperadas. Cuando las empresas no evalúan el desempeño laboral, corren el riesgo que los subordinados enfoquen sus acciones hacia objetivos que se orientan a caminos distintos a los deseados por la organización en cumplimiento de su visión.

Para lograr el objetivo deseado en la adquisición de la competencia fruto de este trabajo, se ha diseñado un proceso para evaluar el desempeño laboral; este proceso comienza con la planificación de la evaluación, para el efecto se analizarán temas como los instrumentos y los métodos utilizados para la evaluación, el tiempo en el que se debe realizar y los responsables de llevar a cabo esta labor. Por otra parte, se darán pautas para concertar los compromisos y los objetivos con los trabajadores, para lo cual se sugiere tener en cuenta las metas establecidas en la planeación estratégica de la empresa, el análisis y la descripción de los cargos, como también los comportamientos que se desean de los trabajadores, en congruencia con la cultura y los valores institucionales; posteriormente, se hace una explicación de cómo hacerle seguimiento a la evaluación; se comparan los resultados fijados versus los concertados; cómo corregir las desviaciones; la evaluación final y los recursos que se pueden interponer ante una evaluación insatisfactoria.

Como estrategia pedagógica para obtener los efectos esperados en la adquisición de la competencia y los conocimientos, se diseñará un taller aplicativo, en el cual el estudiante ponga en práctica las orientaciones dadas en el proceso de evaluación que se diseña, con un caso práctico.

\section{PREFACIO}

Con el desarrollo de la presente unidad, el lector deberá aprender a planificar la evaluación del desempeño, concertar objetivos entre evaluado y evaluador, comparar resultados entre objetivos fijados y los realizados, corregir las desviaciones en el cumplimiento de los objetivos, desarrollar la evaluación final y conocer qué recursos puede tener una evaluación insatisfactoria del evaluado.

Preguntas como: ¿qué es la evaluación del desempeño laboral?; ¿cuál es el proceso para llevar a cabo una evaluación del desempeño laboral?; ¿qué instrumento y método se debe aplicar en una evaluación del desempeño laboral?; ¿cuál es el tiempo adecuado para realizar un evaluación del desempeño laboral?; ¿cómo concertar objetivos en una evaluación del desempeño laboral?; ¿cómo hacer el seguimiento a los objetivos en una evaluación del desempeño laboral?; ¿cómo corregir las desviaciones en el cumplimiento de los objetivos laborales?; ¿qué recursos puede tener el evaluado ante una evaluación del desempeño laboral deficiente?, deben ser resueltas en el desarrollo del presente trabajo. 


\section{DEFINICIÓN DE EVALUACIÓN DEL DESEMPEÑO}

Algunos autores, como R. Wayne Mondy (2010), al referirse a la evaluación del desempeño, manifiestan que:

Es un sistema formal de revisión y evaluación sobre la manera en que un individuo o grupo ejecutan las tareas.... La evaluación del desempeño es especialmente importante en la administración del desempeño. Aunque la evaluación es tan solo un componente de la administración del desempeño, es vital en tanto que refleja de una manera directa el plan estratégico de la organización... Un sistema eficaz de evaluación del desempeño valora los logros e iniciativa planes para el desarrollo, metas y objetivos. (p. 239)

Según Bonnefoy y Armijo (2005), la evaluación del desempeño en el sector privado es:

Básicamente, los indicadores de desempeño al proveer información sobre áreas fundamentales de la acción de los entes públicos tales como la eficiencia, eficacia, calidad, y economía de los recursos, aportan al logro de un mejoramiento de la gestión y a una mayor transparencia de la acción pública. En efecto, contar con una batería de indicadores de desempeño vinculados a la gestión estratégica de las instituciones, apoya la toma de decisiones sobre bases más ciertas, permite mejorar el desempeño y formular el presupuesto sobre criterios más racionales, junto con posibilitar la rendición de cuentas a los diferentes grupos de interés. (p. 5)

Los principios de la evaluación del desempeño laboral son los mismos en el sector privado como en el público, para el caso colombiano, el artículo 125 de la Constitución Política de Colombia establece en uno de sus apartes que el retiro de los funcionarios de carrera administrativa en el sector público se hará: "Por calificación no satisfactoria en el desempeño del empleo; por violación del régimen disciplinario y por las demás causales previstas en la Constitución o la ley" (Constitución Política, 1991, p. 37).

Asimismo, la Ley 909 expedida por el Congreso de la República de Colombia (2004), en su artículo 38 expresa:

El desempeño laboral de los empleados de carrera administrativa deberá ser evaluado y calificado con base en parámetros previamente establecidos que permitan fundamentar un juicio objetivo sobre su conducta laboral y sus aportes al cumplimiento de las metas institucionales. A tal efecto, los instrumentos para la evaluación y calificación del desempeño de los empleados se diseñarán en función de las metas institucionales. (p. 28)

Por último, la Comisión Nacional del Servicio Civil (2008), en el acuerdo 17 del 2008, define la evaluación del desempeño en el Estado Colombiano como:

La evaluación es el proceso mediante el cual se verifican, valoran y califican las realizaciones de una persona en el marco de las funciones y responsabilidades de su desempeño laboral de acuerdo con las condiciones previas establecidas en la etapa de fijación de compromisos laborales, su aporte al logro de las metas institucionales y la generación del valor agregado que deben entregar las instituciones. (p. 1)

La evaluación del desempeño es el proceso mediante el cual se planea, se concertan, se hace seguimiento y comparan, se corrigen y evalúan los objetivos por llevar a cabo por los trabajadores y funcionarios de las organizaciones, con el fin de lograr el éxito empresarial. 


\section{ResPonsABILIDAD DE LA}

\section{EVALUACIÓN DEL DESEMPEÑO}

\section{LABORAL}

La responsabilidad de la evaluación del desempeño laboral dependerá de la estructura y el tamaño de la organización o empresa, así en algunas empresas esta responsabilidad puede recaer en: la gerencia, talento humano, planeación, control interno, el evaluado, el evaluador, el jefe inmediato, etcétera, como se puede ver en la figura 1.

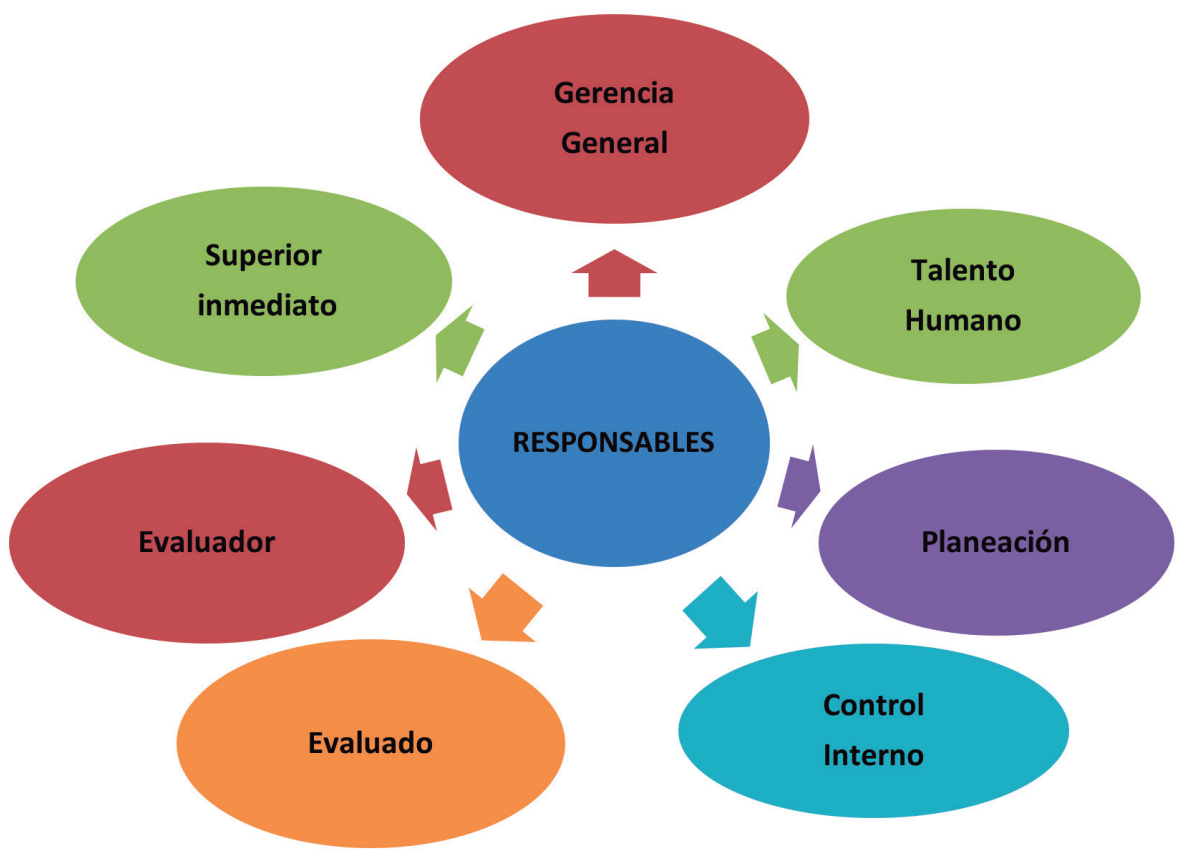

Figura 1. Responsables de la evaluación del desempeño laboral. Elaboración propia.

En tal sentido, la responsabilidad de la evaluación del desempeño en el sector privado dependerá de la estructura y la coyuntura de cada organización; así en algunas empresas la responsabilidad de la evaluación del desempeño es de la gerencia y el departamento de talento humano, en otras exclusivamente de la dependencia de talento humano, etcétera.

\section{¿QUiÉN DEBE EVALUAR EL}

\section{DESEMPEÑO LABORAL EN EL SECTOR PRIVADO?}

Según estudios realizados en países como España y según lo manifiesta Wether y Davis
(2004), se encontró que los superiores inmediatos son los principales evaluadores en una evaluación del desempeño laboral, seguidos por quienes anteceden en jerarquía a los jefes inmediatos y, en tercer lugar, los mismos evaluadores.

Se sugiere, entonces, que en toda evaluación del desempeño laboral esté involucrado de manera directa la persona con la que el evaluado tiene mayor relación de manera ascendente en la jerarquía organizacional, como lo es el superior inmediato; cuando los objetivos que deben cumplir los evaluados tienen relación con terceras personas o entidades o empresas, se debe analizar la intervención de estas en la 
evaluación de desempeño del evaluado, convirtiendo la evaluación en una evaluación compartida o de 360 grados si es necesario. En conclusión, es la empresa la que debe definir quién debe realizar la evaluación del desempeño laboral de los evaluados, para asegurar el cumplimiento de las metas trazadas.

\section{PERIODO EN EL QUE SE}

\section{DESARROLLARÁ LA EVALUACIÓN}

El periodo en que se debe desarrollar la evaluación dependerá de los siguientes aspectos:

- La planeación estratégica de la entidad.

- El tamaño de la empresa.

- La vulnerabilidad y la importancia de los objetivos diseñados.

- El tiempo en el que se debe desarrollar el proceso.

\section{OBjetivos DE LA EVALUACiÓN DEL DESEMPEÑO LABORAL}

Según Alles (2008, p. 32), al referirse a los objetivos de la evaluación del desempeño laboral, afirma que: "Entre sus principales objetivos podemos señalar el desarrollo personal y profesional de colaboradores, la mejora permanente de resultados de la organización y el aprovechamiento adecuado de los recursos humanos".

En el caso del Estado Colombiano, la Comisión Nacional del Servicio Civil (2008, p. 1) establece en el acuerdo 017 del 2008, como finalidad de la evaluación del desempeño en el sector público que:

La evaluación del desempeño laboral tiene como finalidad suministrar a la administración información basada en evidencias que den cuenta de la competencia laboral del empleado, con el fin de orientar la toma de decisiones relacionadas con la permanencia en el servicio, la formulación de planes de incentivos, estímulos y de capacitación y las demás acciones de mejoramiento individual e institucional a que haya lugar.

Por lo tanto, la evaluación del desempeño lo que busca es asegurar que los objetivos diseñados y establecidos en las empresas lleguen a feliz término al llevarse a cabo su cumplimiento; en consecuencia, esta evaluación servirá para tomar los correctivos necesarios para el éxito empresarial e incentivar los comportamientos sobresalientes de los subordinados.

\section{PROCESO PARA EVALUAR EL DESEMPEÑO LABORAL}

Como se ve en la figura 2, el desempeño laboral se puede llevar a cabo en diferentes etapas, en una primera etapa se debe planificar la evaluación; en una segunda etapa se deben concertar los objetivos entre el evaluado y el evaluador; como tercera etapa se debe hacer un seguimiento al evaluado, como cuarta etapa comparar los objetivos concertado versus los ejecutados, en quinto lugar se fijan las acciones correctivas y, por último, se realiza la evaluación final.

\section{Planeación DE LA EVALUACIÓN DEL DESEMPEÑO}

Por una parte, Mejía-Herrera (2019, p. 8), al referirse a la relación existente entre la planeación y la evaluación del desempeño, señala que: "La evaluación del desempeño debe hacerse periódicamente para evitar desviaciones en el cumplimiento de los planes". Por otra, Lévy Leboyer y Prieto (2001), al señalar las etapas de la evaluación del desempeño, mencionan a 
la planeación como una de ellas, en la cual se deben fijar los compromisos y los resultados que deben cumplirse y precisar las condiciones necesarias para el desarrollo de la evaluación.

Por último, en el acuerdo 617 del 2018, la Comisión Nacional del Servicio Civil (2018) establece cuatro fases en la planificación del desempeño laboral en el Estado Colombiano, como se presenta en la figura 3.
En la planeación de la evaluación del desempeño, se debe elegir el instrumento y el método para evaluar, establecer quién o quiénes son los responsables de la evaluación, definir cuál es el periodo por evaluar, identificar cuáles son los objetivos que se van a tener en cuenta en la evaluación, entre otros aspectos.

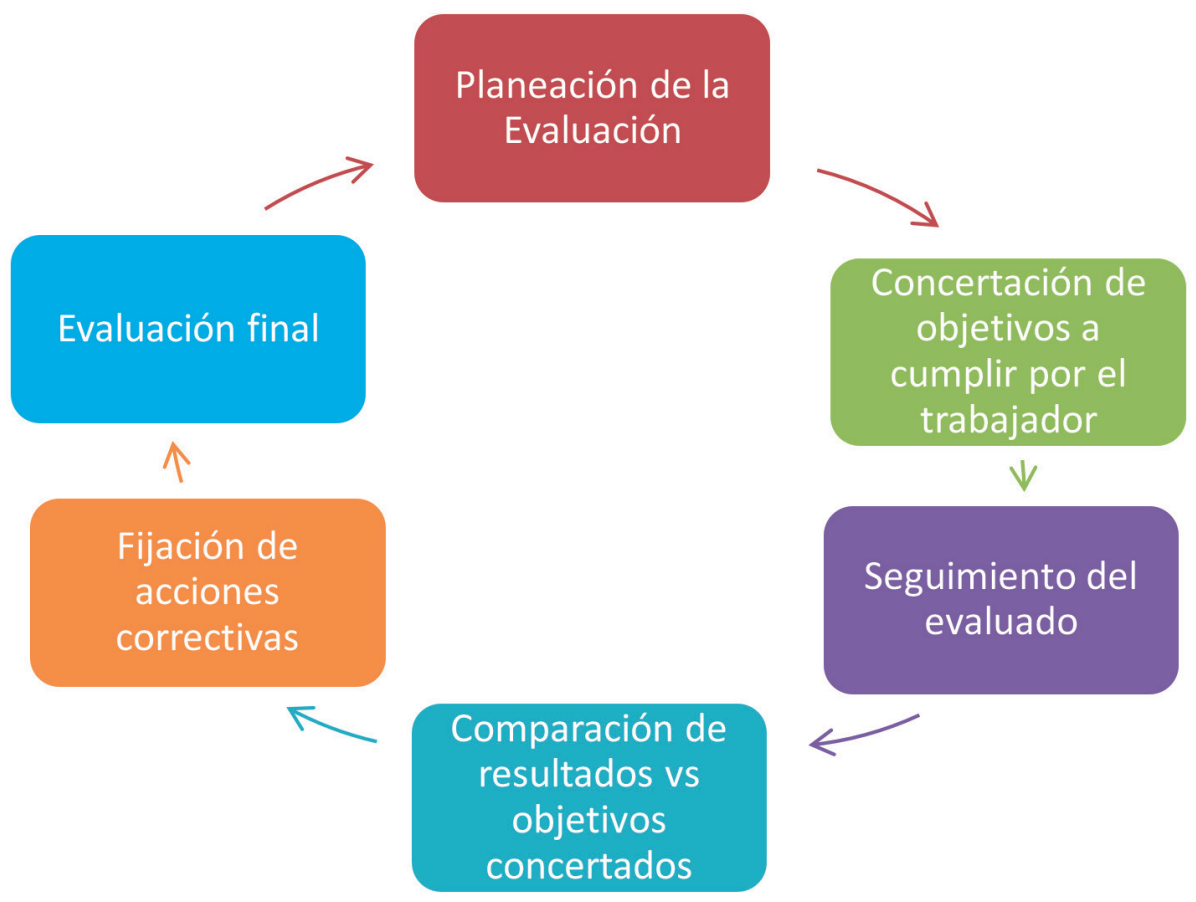

Figura 2. Proceso para evaluar el desempeño laboral en empresas privada. Elaboración propia.

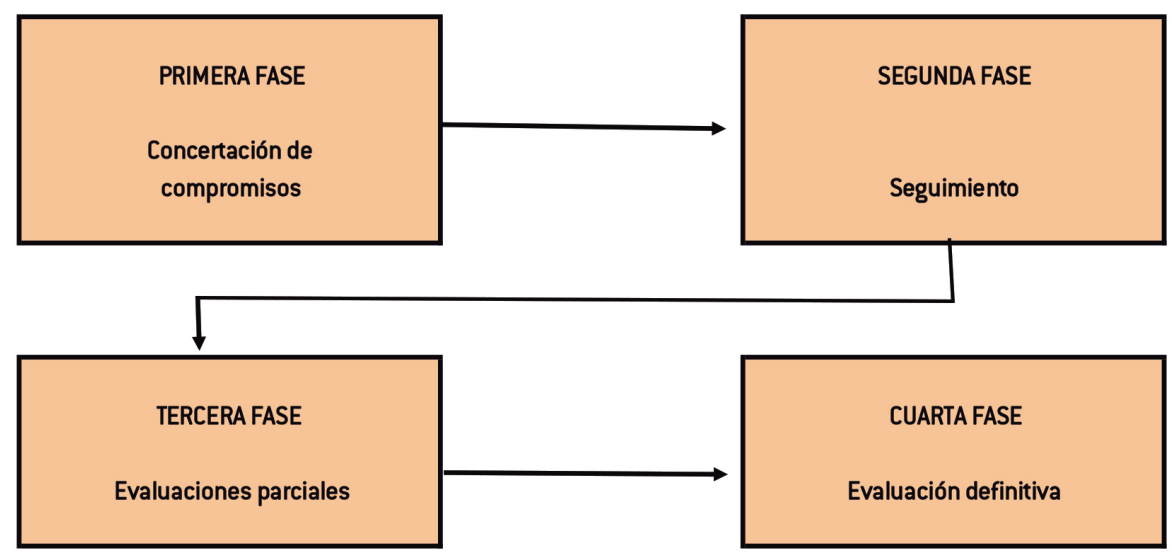

Figura 3. Fases del proceso de evaluación del desempeño en el Estado colombiano. Elaboración propia. 


\section{SELECCIÓN DEL INSTRUMENTO Y MÉTODO DE EVALUACIÓN}

La selección del instrumento y el método de evaluación son los factores de importancia dentro del proceso de evaluación, los instrumentos existentes para evaluar el desempeño laboral son variados y la aplicación de uno de ellos depende de la intencionalidad de la empresa en aras de la objetividad y el cumplimiento de las metas; así la empresa puede seleccionar uno de los siguientes instrumentos de evaluación.

\section{Método de escala gráfica}

Martínez (2012, p. 291) considera que:

Es el método más utilizado dada la sencillez de su aplicación. Se reflejan en un formato de evaluación una serie de características o rasgos personales que se consideran relevantes para el desempeño del puesto. El principio fundamental en que está basado el método es juzgar analíticamente en qué medida una persona posee una determinada característica y qué nivel han alcanzado las diversas características en su prestación de trabajo, en cantidad y calidad.

Chiavenato (2017), al referirse al modelo de escala gráfica, presenta el modelo que se expone en la tabla 1, el cual sirve como instructivo para evaluar el desempeño laboral de los trabajadores con este método.

También es muy utilizado el método de escala gráfica con asignación de puntos según el formato que se muestra en la tabla 2.

\section{Método de elección forzada}

Este método es llamado por Dessler (2015, p. 234) como distribución forzada y expresa que: "Es similar a clasificar utilizando una curva, es decir, se establecen porcentajes predeterminados de empleados calificados para diversas categorías de desempeño". Para Chiavenato (2017, p. 255), una de las características de este metodo consiste en:

Evaluar el desempeño de las personas por medio de frases alternativas que describen el tipo de desempeño individual. Cada bloque está compuesto por dos, cuatro o más frases y el evaluador está obligado a escoger solo una o dos de las que explican mejor el desempeño de la persona evaluada, por eso se llama elección forzosa.

El instructivo que se puede utilizar para este método se expone en la tabla 3.

\section{Método de comparación por pares}

Dessler (2015, p. 234) manifiesta que:

$$
\begin{aligned}
& \text { El método de comparación por pares sir- } \\
& \text { ve para que el método de clasificación } \\
& \text { sea más preciso. Para cada característica } \\
& \text { (cantidad de trabajo, calidad del trabajo, } \\
& \text { etcétera), se parea y compara a cada su- } \\
& \text { bordinado con cada uno de los otros em- } \\
& \text { pleados. }
\end{aligned}
$$

Este método consiste en comparar el desempeño de un trabajador con otro en los diferentes campos de la competitividad y cumplimiento que la empresa establece para alcanzarlos objetivos organizacionales. Un ejemplo del instructivo con este método se muestra en la tabla 4. 
TABLA 1. Modelo del método de escalas gráficas

\begin{tabular}{|c|c|}
\hline & EVALUACIÓN DEL DESEMPEÑO \\
\hline Nombre del trabajador: & \\
\hline Departamento/Sección: & \\
\hline
\end{tabular}

\begin{tabular}{|c|c|c|c|c|c|}
\hline \multicolumn{6}{|c|}{ Desempeño en la función: considerar exclusivamente el desempeño actual del trabajador en su función } \\
\hline & Óptimo & Bueno & Regular & Tolerable & Malo \\
\hline $\begin{array}{l}\text { Producto } \\
\text { Volumen y cantidad de trabajo } \\
\text { ejecutados normalmente }\end{array}$ & $\begin{array}{l}\text { Siempre más allá } \\
\text { de lo exigido muy } \\
\text { rápido }\end{array}$ & $\begin{array}{c}\text { Con frecuencia } \\
\text { va más allá de lo } \\
\text { exigido }\end{array}$ & $\begin{array}{l}\text { Satisface lo } \\
\text { exigido }\end{array}$ & $\begin{array}{l}\text { A veces está } \\
\text { por debajo de lo } \\
\text { exigido }\end{array}$ & $\begin{array}{l}\text { Siempre esta } \\
\text { por debajo de } \\
\text { lo exigido. Muy } \\
\text { lento }\end{array}$ \\
\hline $\begin{array}{l}\text { Cualidad } \\
\text { Exactitud, esmero y orden en } \\
\text { el trabajo ejecutado }\end{array}$ & $\begin{array}{l}\text { Siempre superior. } \\
\text { Excepcionalmen- } \\
\text { te exacto en su } \\
\text { trabajo }\end{array}$ & $\begin{array}{l}\text { A veces superior. } \\
\text { Bastante exacto } \\
\text { en su trabajo }\end{array}$ & $\begin{array}{c}\text { Siempre } \\
\text { satisfactorio. } \\
\text { Su exactitud es } \\
\text { regular }\end{array}$ & $\begin{array}{l}\text { Parcialmente } \\
\text { satisfactorio. En } \\
\text { ocasiones pre- } \\
\text { senta errores }\end{array}$ & $\begin{array}{l}\text { Nunca satisfac- } \\
\text { torio. Presenta } \\
\text { gran cantidad de } \\
\text { errores }\end{array}$ \\
\hline $\begin{array}{l}\text { Conocimiento del trabajo } \\
\text { Grado de conocimiento del trabajo }\end{array}$ & $\begin{array}{l}\text { Sabe todo lo ne- } \\
\text { cesario y no cesa } \\
\text { de aumentar sus } \\
\text { conocimientos }\end{array}$ & $\begin{array}{l}\text { Sabe lo nece- } \\
\text { sario }\end{array}$ & $\begin{array}{l}\text { Sabe suficiente } \\
\text { del trabajo }\end{array}$ & $\begin{array}{l}\text { Sabe parte del } \\
\text { trabajo. Necesita } \\
\text { capacitación }\end{array}$ & $\begin{array}{l}\text { Sabe poco del } \\
\text { trabajo }\end{array}$ \\
\hline $\begin{array}{c}\text { Cooperación } \\
\text { Actitud ante la empresa, } \\
\text { el jefe y sus colegas }\end{array}$ & $\begin{array}{l}\text { Tiene un exce- } \\
\text { lente espíritu de } \\
\text { colaboración. } \\
\text { Gran empeño }\end{array}$ & $\begin{array}{l}\text { Funciona bien } \\
\text { en el trabajo en } \\
\text { equipo. Procura } \\
\text { colaborar }\end{array}$ & $\begin{array}{l}\text { Normalmente } \\
\text { colabora en el } \\
\text { trabajo en equipo }\end{array}$ & $\begin{array}{l}\text { No demuestra } \\
\text { buena disposi- } \\
\text { ciones. Solo co- } \\
\text { labora cuando es } \\
\text { muy necesario }\end{array}$ & $\begin{array}{l}\text { Es reticente a } \\
\text { colaborar }\end{array}$ \\
\hline
\end{tabular}

\begin{tabular}{|c|}
\hline Características individuales: considerar tan solo las características individuales del evaluado \\
y su comportamiento funcional dentro y fuera de su función
\end{tabular}

\begin{tabular}{|c|c|c|c|c|c|}
\hline $\begin{array}{l}\text { Comprensión de las situaciones } \\
\text { Grado en que percibe la esencia de un } \\
\text { problema. Capaz de plegarse a situacio- } \\
\text { nes y desplegar tareas }\end{array}$ & $\begin{array}{l}\text { Óptima intuición } \\
\text { y capacidad de } \\
\text { percepción }\end{array}$ & $\begin{array}{l}\text { Buena intuición } \\
\text { y capacidad de } \\
\text { percepción }\end{array}$ & $\begin{array}{l}\text { Satisfactoria } \\
\text { intuición y } \\
\text { capacidad de } \\
\text { percepción }\end{array}$ & $\begin{array}{l}\text { Poca intuición } \\
\text { y capacidad de } \\
\text { percepción }\end{array}$ & $\begin{array}{l}\text { Ninguna intui- } \\
\text { ción y capacidad } \\
\text { de percepción }\end{array}$ \\
\hline $\begin{array}{c}\text { Creatividad } \\
\text { Empeño. } \\
\text { Capacidad para crear ideas y proyectos }\end{array}$ & $\begin{array}{l}\text { Siempre tiene } \\
\text { ideas óptimas. } \\
\text { Tipo creativo y } \\
\text { original }\end{array}$ & $\begin{array}{l}\text { Casi siempre tie- } \\
\text { ne buenas ideas } \\
\text { y proyectos }\end{array}$ & $\begin{array}{l}\text { Algunas veces } \\
\text { presenta suge- } \\
\text { rencias }\end{array}$ & $\begin{array}{l}\text { Levemente } \\
\text { rutinario. Tiene } \\
\text { pocas ideas } \\
\text { propias }\end{array}$ & $\begin{array}{l}\text { Tipo rutinario. } \\
\text { No tiene ideas } \\
\text { propias }\end{array}$ \\
\hline $\begin{array}{l}\text { Capacidad de realización } \\
\text { Capacidad para poner en práctica } \\
\text { ideas y proyectos }\end{array}$ & $\begin{array}{l}\text { Capacidad } \\
\text { óptima para con- } \\
\text { cretar nuevas } \\
\text { ideas }\end{array}$ & $\begin{array}{c}\text { Buena capacidad } \\
\text { para concretar } \\
\text { nuevas ideas }\end{array}$ & $\begin{array}{c}\text { Realiza y pone } \\
\text { en práctica } \\
\text { nuevas ideas } \\
\text { con habilidad } \\
\text { satisfactoria }\end{array}$ & $\begin{array}{l}\text { Tiene dificultad } \\
\text { para concretar } \\
\text { nuevos } \\
\text { proyectos }\end{array}$ & $\begin{array}{l}\text { Incapaz de poner } \\
\text { en práctica una } \\
\text { idea o proyecto } \\
\text { cualquiera }\end{array}$ \\
\hline
\end{tabular}

Nota. Tomado de Chiavenato (201?). 
TABLA 2. Método de escala gráfica con utilización de puntos

\begin{tabular}{|c|c|}
\hline EVALUACIÓN DEL EMPLEADO \\
\hline Nombre completo_ Fecha: $\_$Puesto: \\
\hline Sección:
\end{tabular}

Cada factor fue dividido en el número de calificaciones aplicadas. Considere cada uno por separado, asignando una sola calificación a cada factor, indique el valor de los puntos en las columnas de la derecha.

\begin{tabular}{|c|c|c|c|c|c|c|}
\hline Factor de evaluación & \multicolumn{5}{|c|}{ Grado } & \multirow[t]{2}{*}{ Puntos } \\
\hline \multirow[b]{2}{*}{$\begin{array}{c}\text { 1. Producción: evalué el tra- } \\
\text { bajo producido o la cantidad } \\
\text { de servicios. }\end{array}$} & $1-2-3$ & $4-5-6$ & $7-8-9$ & $10-11-12$ & $13-14-15$ & \\
\hline & $\begin{array}{l}\text { Producción } \\
\text { inadecuada }\end{array}$ & $\begin{array}{l}\text { Producción ape- } \\
\text { nas aceptable }\end{array}$ & $\begin{array}{l}\text { Producción } \\
\text { satisfactoria, } \\
\text { pero sin nada de } \\
\text { especial }\end{array}$ & $\begin{array}{l}\text { Siempre man- } \\
\text { tiene una buena } \\
\text { producción }\end{array}$ & $\begin{array}{l}\text { Siempre da } \\
\text { cuenta de un vo- } \\
\text { lumen realmente } \\
\text { sobresaliente de } \\
\text { servicio }\end{array}$ & \\
\hline \multirow[b]{2}{*}{$\begin{array}{l}\text { 2. Calidad: evalué la exacti- } \\
\text { tud. La frecuencia de los erro- } \\
\text { res, la presentación, el orden } \\
\text { y el esmero que caracterizan } \\
\text { el servicio del empleado. }\end{array}$} & $1-2-3$ & $4-5-6$ & $7-8-9$ & $10-11-12$ & $13-14-15$ & \\
\hline & $\begin{array}{l}\text { Comete demasia- } \\
\text { dos errores y el } \\
\text { servicio demues- } \\
\text { tra desorden y } \\
\text { falta de cuidado }\end{array}$ & $\begin{array}{l}\text { Generalmente } \\
\text { satisfactorio, } \\
\text { pero a veces deja } \\
\text { algo por desear }\end{array}$ & $\begin{array}{l}\text { En general, tra- } \\
\text { baja con cuidado }\end{array}$ & $\begin{array}{l}\text { Siempre hace } \\
\text { bien su trabajo }\end{array}$ & $\begin{array}{l}\text { Su trabajo de- } \\
\text { muestra cuidado } \\
\text { excepcional }\end{array}$ & \\
\hline \multirow[b]{2}{*}{$\begin{array}{l}\text { 3. Responsabilidad: evalué } \\
\text { la dedicación al trabajo y si } \\
\text { brinda el servicio dentro del } \\
\text { plazo estipulado. Considere } \\
\text { la supervisión necesaria } \\
\text { para obtener los resultados } \\
\text { deseados. }\end{array}$} & $1-2-3$ & $4-5-6$ & $7-8-9$ & $10-11-12$ & $13-14-15$ & \\
\hline & $\begin{array}{l}\text { Es imposible } \\
\text { depender se sus } \\
\text { servicios y ne- } \\
\text { cesita vigilancia } \\
\text { constante }\end{array}$ & $\begin{array}{l}\text { No siempre se } \\
\text { puede contar } \\
\text { con resultados } \\
\text { deseados si } \\
\text { no cuenta con } \\
\text { bastante super- } \\
\text { visión }\end{array}$ & $\begin{array}{c}\text { Se puede } \\
\text { depender de él o } \\
\text { ella aplicándole } \\
\text { una supervisión } \\
\text { normal }\end{array}$ & $\begin{array}{l}\text { Tiene buena } \\
\text { dedicación y } \\
\text { basta con darle } \\
\text { una pequeña } \\
\text { directriz }\end{array}$ & $\begin{array}{l}\text { Merece el máxi- } \\
\text { mo de confianza. } \\
\text { No necesita } \\
\text { supervisión } \\
\text { alguna }\end{array}$ & \\
\hline \multirow[b]{2}{*}{$\begin{array}{l}\text { 4. Cooperación. Actitud: } \\
\text { pondere la voluntad para } \\
\text { cooperar, la ayuda que presta } \\
\text { a los colegas, la manera de } \\
\text { acatar órdenes. }\end{array}$} & $1-2-3$ & $4-5-6$ & $7-8-9$ & $10-11-12$ & $13-14-15$ & \\
\hline & $\begin{array}{l}\text { Poco dispuesto } \\
\text { a cooperar y } \\
\text { constantemente } \\
\text { demuestra falta } \\
\text { de educación }\end{array}$ & $\begin{array}{l}\text { A veces difícil } \\
\text { de lidiar. Le falta } \\
\text { entusiasmo }\end{array}$ & $\begin{array}{l}\text { Generalmente, } \\
\text { cumple con } \\
\text { buena actitud lo } \\
\text { que se le dice. } \\
\text { Está satisfecho } \\
\text { con su trabajo }\end{array}$ & $\begin{array}{l}\text { Siempre dispues- } \\
\text { to a cooperary } \\
\text { a ayudar a los } \\
\text { colegas }\end{array}$ & $\begin{array}{l}\text { Coopera al máxi- } \\
\text { mo. Se esfuerza } \\
\text { por ayudar a sus } \\
\text { colegas }\end{array}$ & \\
\hline \multirow[b]{2}{*}{$\begin{array}{l}\text { 5. Sentido común e inicia- } \\
\text { tiva: considere el sentido } \\
\text { común de las decisiones, la } \\
\text { ausencia de instrucciones } \\
\text { detalladas o la situaciones } \\
\text { fuera de lo común. }\end{array}$} & $1-2-3$ & $4-5-6$ & $7-8-9$ & $10-11-12$ & $13-14-15$ & \\
\hline & $\begin{array}{c}\text { Siempre toma la } \\
\text { decisión equivo- } \\
\text { cada }\end{array}$ & $\begin{array}{l}\text { Se engaña con } \\
\text { frecuencia y } \\
\text { es conveniente } \\
\text { proporcionarle } \\
\text { instrucciones } \\
\text { detallas }\end{array}$ & $\begin{array}{l}\text { Demuestra } \\
\text { razonable sen- } \\
\text { tido común en } \\
\text { circunstancias } \\
\text { normales }\end{array}$ & $\begin{array}{l}\text { Resuelve los pro- } \\
\text { blemas normal- } \\
\text { mente con un } \\
\text { grado elevado de } \\
\text { sentido común }\end{array}$ & $\begin{array}{l}\text { En todas las si- } \\
\text { tuaciones piensa } \\
\text { con velocidad y } \\
\text { lógica. Siempre } \\
\text { se puede confiar } \\
\text { en sus decisio- } \\
\text { nes }\end{array}$ & \\
\hline \multirow{2}{*}{$\begin{array}{l}\text { 6. Presentación personal: } \\
\text { considere la impresión que } \\
\text { la presentación personal del } \\
\text { empleado produce en otros, } \\
\text { su forma de vestir, su arreglo } \\
\text { personal, su cabello, su } \\
\text { barba, etc. }\end{array}$} & $1-2-3$ & $4-5-6$ & $7-8-9$ & $10-11-12$ & $13-14-15$ & \\
\hline & $\begin{array}{l}\text { Relajado. Descui- } \\
\text { dado }\end{array}$ & $\begin{array}{l}\text { A veces descuida } \\
\text { su aspecto }\end{array}$ & $\begin{array}{l}\text { Normalmente } \\
\text { está bien arre- } \\
\text { glado }\end{array}$ & $\begin{array}{l}\text { Cuidadoso en su } \\
\text { forma de vestiry } \\
\text { de presentarse }\end{array}$ & $\begin{array}{l}\text { Excepcionalmen- } \\
\text { te bien cuidado y } \\
\text { presentable }\end{array}$ & \\
\hline \multicolumn{6}{|c|}{ TOTAL DE PUNTOS } & \\
\hline
\end{tabular}

Nota. Tomado de Chiavenato (2017). 
TABLA 3. Método de elección forzada

\begin{tabular}{|c|c|}
\hline & EVALUA \\
\hline Trabajad & \\
\hline Puesto: & Sección/Departamento: \\
\hline
\end{tabular}

A continuación, encontrará frases del desempeño combinadas en bloques de cuatro. En las columnas laterales, anote una "X" debajo del signo "+" para indicar la frase que mejor describa el desempeño del empleado y del signo "-" para la frase que menos define su desempeño. No deje ningún bloque sin marcar dos veces.

\begin{tabular}{|l|c|c|c|l|c|c|}
\hline Solo hace lo que le mandan & N. ${ }^{0} 01$ & + & - & Tiene miedo de pedir ayuda & N. ${ }^{0} 41$ & + \\
\hline Comportamiento irreprochable & 02 & & & Siempre tiene su archivo en orden & 42 & \\
\hline Acepta críticas constructivas & 03 & & & Baja producción & 43 & \\
\hline No produce cuando esta bajo presión & 04 & & & Es dinámico & 44 & \\
\hline
\end{tabular}

\begin{tabular}{|l|l|l|l|l|c|c|}
\hline Cortes con terceros & 05 & & & Interrumpe constantemente el trabajo & 45 & \\
\hline Duda para tomar decisiones & 06 & & & No se somete a influencias & 46 & \\
\hline Merece toda la confianza & 07 & & & Tiene buen potencial para ser desenvuelto & 47 & \\
\hline Tiene poca iniciativa & 08 & & & Nunca es desagradable & 48 & \\
\hline
\end{tabular}

\begin{tabular}{|l|c|c|l|l|c|c|}
\hline Caprichoso al brindar el servicio & 33 & & & Nunca hace buenas sugerencias & 73 & \\
\hline No tiene formación adecuada & 34 & & & Se nota que "le gusta lo que hace" & 74 & \\
\hline Tiene buena apariencia personal & 35 & & & Tiene buena memoria & 75 & \\
\hline En su servicio siempre hay errores & 36 & & & Le gusta reclamar & 76 & \\
\hline
\end{tabular}

\begin{tabular}{|c|c|c|c|}
\hline Se expresa con dificultad & 37 & Impone su criterio al tomar decisiones & 7? \\
\hline Conoce su trabajo & 38 & Se le debe llamar la atención regularmente & 78 \\
\hline $\begin{array}{l}\text { Cuidadoso con las instalaciones de la } \\
\text { empresa }\end{array}$ & 39 & Es rápido & 79 \\
\hline Siempre espera obtener un premio & 40 & Es de naturaleza un poco hostil & 80 \\
\hline
\end{tabular}

Nota. Tomado de Chiavenato [2017).

TABLA 4. Método de comparación por pares

\begin{tabular}{|c|c|c|c|c|c|c|}
\hline \multicolumn{6}{|c|}{ PRODUCTIVIDAD } & \multirow[t]{2}{*}{ PROMEDIO EVALUACIÓN } \\
\hline TRABAJADOR & A & $B$ & C & D & $E$ & \\
\hline A & & & & & & \\
\hline B & & & & & & \\
\hline C & & & & & & \\
\hline $\mathrm{D}$ & & & & & & \\
\hline$E$ & & & & & & \\
\hline \multicolumn{3}{|c|}{ CALIDAD DE TRABAJO } & & & & PROMEDIO EVALUACIÓN \\
\hline TRABAJADOR & A & B & C & $\mathrm{D}$ & $E$ & \\
\hline A & & & & & & \\
\hline $\mathrm{B}$ & & & & & & \\
\hline C & & & & & & \\
\hline $\mathrm{D}$ & & & & & & \\
\hline$E$ & & & & & & \\
\hline
\end{tabular}




\begin{tabular}{|c|c|c|c|c|c|c|}
\hline \multicolumn{6}{|c|}{ CREATIVIDAD } & PROMEDIO EVALUACIÓN \\
\hline TRABAJADOR & A & B & c & D & $\mathrm{E}$ & \\
\hline A & & & & & & \\
\hline B & & & & & & \\
\hline c & & & & & & \\
\hline D & & & & & & \\
\hline $\mathrm{E}$ & & & & & & \\
\hline \multicolumn{6}{|c|}{ LIDERAZGO } & PROMEDIO EVALUACIÓN \\
\hline TRABAJADOR & A & B & C & $\mathrm{D}$ & $\mathrm{E}$ & \\
\hline A & & & & & & \\
\hline $\mathrm{B}$ & & & & & & \\
\hline c & & & & & & \\
\hline D & & & & & & \\
\hline $\mathrm{E}$ & & & & & & \\
\hline
\end{tabular}

Nota. Elaboración propia.

\section{Método de incidentes críticos}

Este método se enfoca en el comportamiento humano, sus acciones a través de determinadas actividades. Chiavenato (2017, p. 222) afirma que:

Este método se basa en el hecho de que en el comportamiento humano existen ciertas características fundamentales capaces de llevar a resultados positivos (éxito) o negativos (fracaso). Es una técnica sistemática por medio de la cual cada superior inmediato investiga, observa y registra los hechos, positivos o negativos, más destacados del desempeño de cada subordinado en sus tareas. Este método puede dividirse en tres fases: en la fase uno, observación del comportamiento de los subordinados. El superior inmediato hace seguimiento y observa detallada y cuidadosamente el comportamiento de sus subordinados en el desempeño de sus tareas. En la fase dos, registro de hechos significativos. El superior inmediato anota y registra todos los hechos realmente significativos y destacados del comportamiento del subordinado, o sea, todos los incidentes críticos, que podrán referirse al desempeño altamente positivo (éxito) o el desempeño altamente negativo (fracaso). Y en la fase tres, investigación de la aptitud y el comportamiento. Esta fase se desarrolla en intervalos regulares de tiempo, mediante entrevistas entre el superior inmediato y el empleado evaluado.

Para Castillo Aponte (2008, p. 308), con este método, "el supervisor inmediato debe anotar los comportamientos destacados del trabajador, ya sean estos positivos o negativos. Aunque tedioso y consumidor de tiempo, esta técnica puede ser utilizada para respaldar la evaluación que se emita mediante otro método".

\section{Método de frases descriptivas}

Chiaventato (2017, p. 261) afirma que:

Este método solo difiere del método de la elección forzosa en que no es obligatorio escoger las frases. El evaluador señala las frases que caracterizan el desempeño del subordinado (señal “+” o "S") y aquellas que muestran el desempeño contrario (signo “-” o "N"). 
En este método se tienen en cuenta diferentes factores los cuales ayudan a identificar ciertos aspectos que ayudarán a decidir qué tal ha sido el desempeño del trabajador. En la tabla 6 se tiene un ejemplo.

\section{Evaluación de 360 grados}

Alles M. (2010, p. 148) se refiere a la evaluación de 360 grados de la siguiente manera:

Es un esquema sofisticado que permite que un empleado sea evaluado por todo su entorno: jefes, pares y colaboradores. Puede incluir otras personas como proveedores o clientes. En una primera instancia se incluirán opiniones de diversos autores y, sobre el final del capítulo, presentaremos nuestra propuesta.
Flores Mendoza y Cervantes Penagos (2019, p. 164) consideran que:

Todos los individuos que tienen alguna interacción con el evaluado, califican su desempeño. Son observadores: el superior, los compañeros, los pares, los subordinados, los clientes internos y externos, los proveedores y todas las personas a su alrededor, (de ahí su nombre de 360 grados).

Una evaluación de 360 grados implica que todos los stakeholders que son de importancia para el sostenimiento y el mantenimiento de la empresa, evalúen la conducta, el comportamiento y el accionar de los trabajadores, con el fin de orientarlos a su plena satisfacción, cumpliendo con la visión, misión institucional y los objetivos corporativos, como se muestra en la figura 4.

TABLA 5. Método de incidentes críticos

\begin{tabular}{|l|l|l|l|}
\hline \multicolumn{2}{|l|}{ Evaluación de desempeño } \\
\hline Nombre: & \multicolumn{1}{|c|}{ Aspectos excepcionalmente negativos } \\
\hline Cargo: & & Presenta muchos errores \\
\hline \multicolumn{2}{|c|}{ Aspectos excepcionalmente positivos } & & Falta de visión general del tema \\
\hline Sabe tratar con las personas & & Demora en toma de decisiones \\
\hline Facilidad para trabajar en equipo & & Espíritu conservador y limitado \\
\hline Presenta ideas innovadoras & & Dificultad para manejar números \\
\hline Tiene características de liderazgo & & Comunicación deficiente \\
\hline Facilidad de argumentación & & \\
\hline Espíritu muy emprendedor & & \\
\hline
\end{tabular}

Nota. Tomado de López Carrillo (2013).

TABLA 6. Método de frases descriptivas

\begin{tabular}{|c|l|c|c|}
\hline $\mathbf{N} .^{\circ}$ & \multicolumn{1}{|c|}{ Factores de evaluación del desempeño } & Sí $[+]$ & No $[-]$ \\
\hline 1 & ¿Tiene estudios suficientes para desempeñar el puesto? & & \\
\hline 2 & ¿Acostumbra estar alegre y sonriente? & & \\
\hline 3 & ¿Tiene experiencia en las actividades que está realizando? & & \\
\hline 4 & ¿Se opone a los cambios y no le interesan las ideas nuevas? & & \\
\hline 5 & ¿Tiene conocimiento de información y de procesos de producción que no deben llegar a terceros? & & \\
\hline 6 & ¿Desarrolla un trabajo complejo y presta atención a las instrucciones recibidas? & \\
\hline
\end{tabular}




\begin{tabular}{|c|l|c|c|}
\hline N. ${ }^{\circ}$ & \multicolumn{1}{|c|}{ Factores de evaluación del desempeño } & Sí $[+]$ & No $[-]$ \\
\hline 7 & ¿Demuestra atracción por el sexo opuesto? & & \\
\hline 8 & ¿Manifiesta interés por aprender cosas nuevas? & & \\
\hline 9 & ¿Su trabajo no requiere más escolaridad? & & \\
\hline 10 & ¿Puede planear, ejecutar y controlar él solo las tareas? & & \\
\hline 11 & ¿Su aspecto, en general, es bueno y agradable frente a los contactos? & & \\
\hline 12 & ¿Exhibe concentración mental en sus actividades? & & \\
\hline 13 & ¿La atención en el trabajo exige que él esfuerce la vista? & & \\
\hline 14 & ¿Presta atención a las condiciones de trabajo, principalmente al orden? & & \\
\hline 15 & ¿El resultado del trabajo tiene errores y no es satisfactorio? & & \\
\hline 16 & ¿Se recomienda un curso de especialización para que progrese en el trabajo? & \\
\hline 17 & ¿Fuma? & & \\
\hline 18 & ¿Es desaliñado en su presentación personal y su forma de vestir? & \\
\hline 19 & ¿Se cuida durante su trabajo y hace lo mismo con sus compañeros? & \\
\hline 20 & ¿Si tuviera más conocimiento de los trabajos podría rendir más? & \\
\hline 21 & ¿Observa con cuidado el desempeño de las máquinas con las que trabaja? & \\
\hline 22 & ¿No se esfuerza demasiado al realizar las tareas? & \\
\hline 23 & ¿Su productividad es loable? & \\
\hline 24 & ¿A pesar de que siempre hace lo mismo, no le molesta la repetición? & \\
\hline 25 & ¿Tiene fama de que nunca tiene dinero en el bolsillo? & \\
\hline
\end{tabular}

Nota. Tomado de Chiavenato [201?].

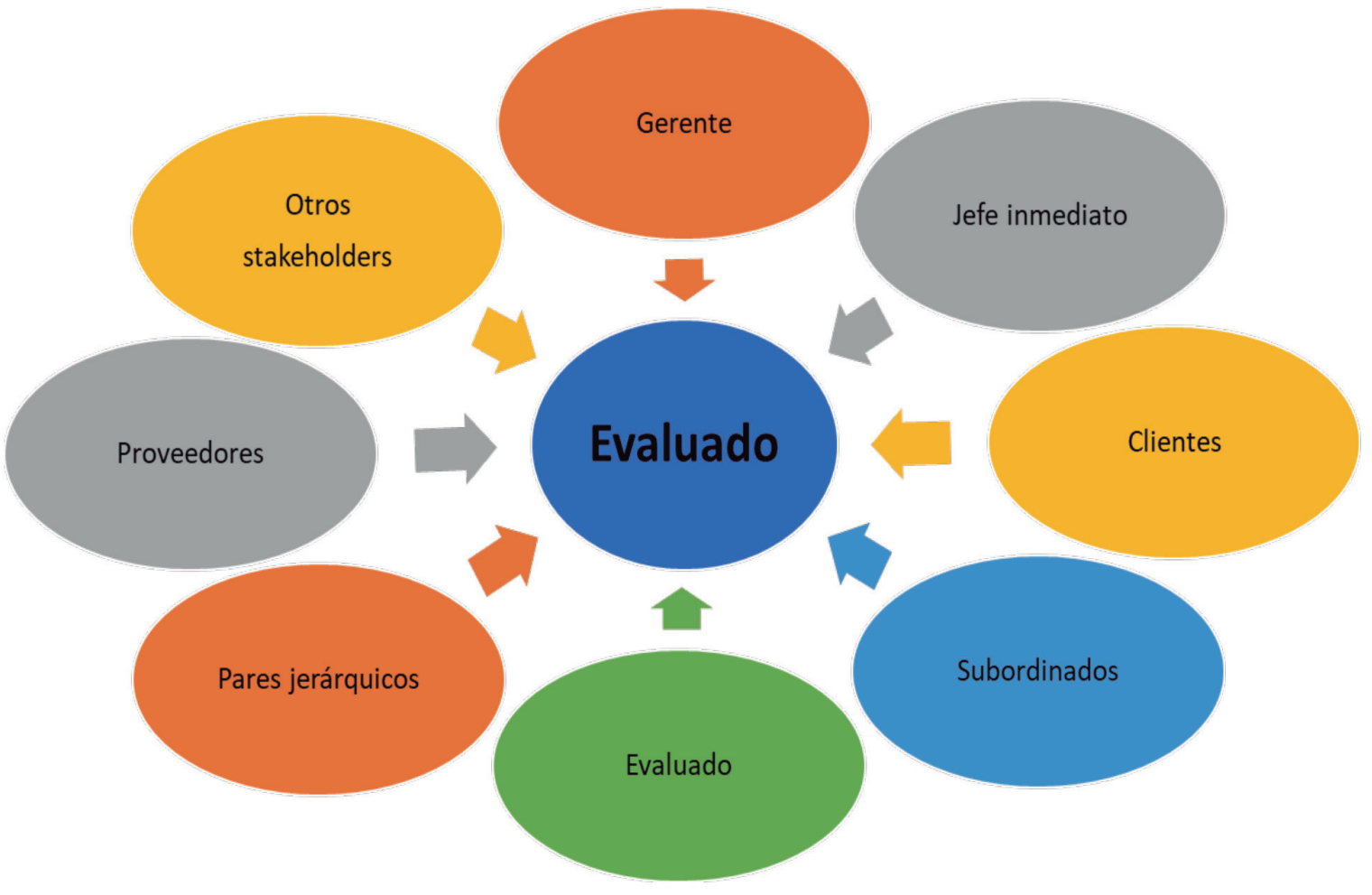

FIGURA 4. Evaluación de 360 grados. Elaboración propia. 


\section{Otros métodos de evaluación del} desempeño laboral

Existen otros métodos de evaluación del desempeño laboral como lo son: evaluar por resultados, extraída del modelo de administración por objetivos de Peter Druker, estudiado por Koontz, Weihrich y Cannice (2012); la autoevaluación, que tiene, como lo afirma Galpin (2013), como aspectos positivos, que involucra al evaluado en la medición, por otro lado, motiva a las personas a convertirse en algo importante para ellas y, por último, invita a que el mismo evaluado se cuestione; otro es el método mixto, que es una combinación de los anteriores.

\section{Método de evaluación por compromisos}

El método de evaluación por compromisos propuesto en el presente trabajo consiste en evaluar el desempeño laboral de los trabajadores, teniendo en cuenta los compromisos laborales, que tiene, relación directa con los objetivos estratégicos de la empresa y los compromisos de comportamiento del trabajador que guardan una relación estrecha y se enmarcan dentro de la cultura y los valores corporativos.

El instrumento utilizado para evaluar bajo este método corresponde al que debe utilizar el jefe inmediato o persona que tenga una relación directa con el evaluado y con quien debe concertar los objetivos que se fijarán en la evaluación; de esta manera, cuando la empresa desea que otros actores o stakeholders participen en la evaluación, en estos casos se deben definir las variables que son de interés para la organización y que desean evaluar y las cuales pueden no contenerlas el instructivo aquí diseñado. En la tabla 7 se muestra el instructivo para llevar a cabo la evaluación con este método y las instrucciones para su diligenciamiento.

Instructivo para diligenciar el instrumento o modelo para evaluar el desempeño laboral en las empresas del sector privado:

1. Información del evaluado y el evaluador. Se registran los nombres tanto del evaluado como del evaluador, con documento de identidad, cargo que ocupan, el nivel jerárquico de cada cargo y la dependencia a la que pertenecen.

2. Objetivos estratégicos relacionados con el cargo. Se debe revisar el plan estratégico de la empresa y relacionar aquellos objetivos que tengan relación directa con el cargo del evaluado.

3. Periodo evaluado. Se registra el periodo establecido por la empresa, para desarrollar la evaluación. En caso de que durante el periodo se den varias evaluaciones parciales, la evaluación definitiva será el promedio de estas.

4. Compromisos laborales. a) En la parte de compromisos orientados al cumplimiento de los objetivos se relacionan aquellas metas que tienen relación directa con los objetivos establecidos en la planeación estratégica y el cargo del evaluado; b) en las evidencias se registra la información de importancia que tenga que ver con el cumplimiento de los objetivos; c) y d) en la primera y segunda evaluación del periodo, se registra el peso porcentual que el evaluador como representante de la empresa le asigna a cada objetivo, teniendo en cuenta que la sumatoria de los pesos porcentuales asignados debe ser igual al 100\%, en la parte de puntos, se registra los puntos de 1 a 100, dado el cumplimiento del evaluado en cada uno de ellos; e) la calificación es el promedio de las dos evaluaciones parciales otorgadas, de la siguiente manera: en la primera evaluación se multiplican los puntos dados en el cumplimiento de los objetivos por el peso porcentual de cada uno de ellos, igual procedimiento se hace para la segunda evaluación, en la parte de calificación, se multiplican los puntos de la primera y segunda evaluación por los porcentajes de cada una de ellas y este resultado se divide en dos, así, la sumatoria no podrá ser superior a 100 puntos. En la tabla 8 se puede ver un ejemplo. 


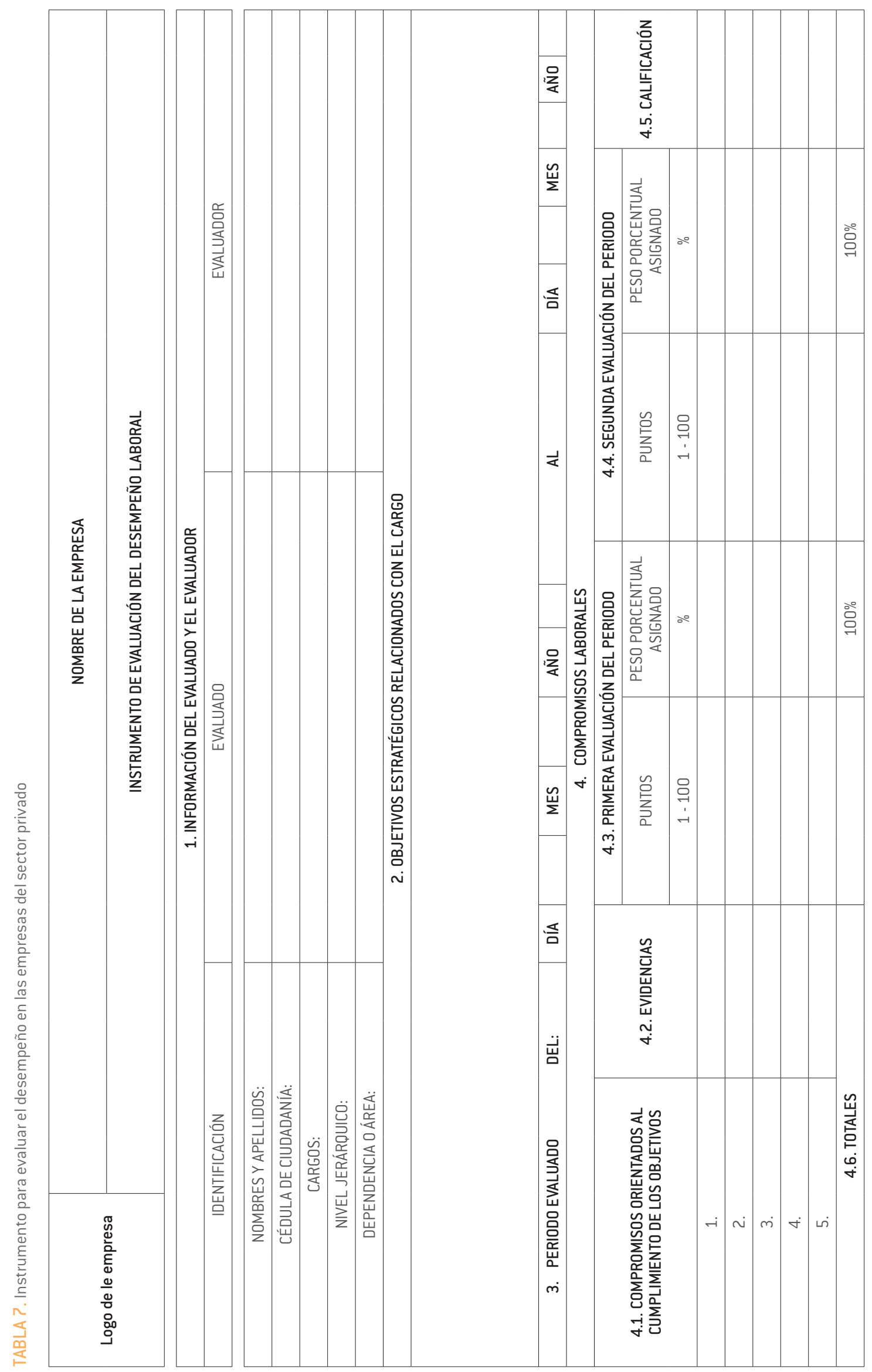




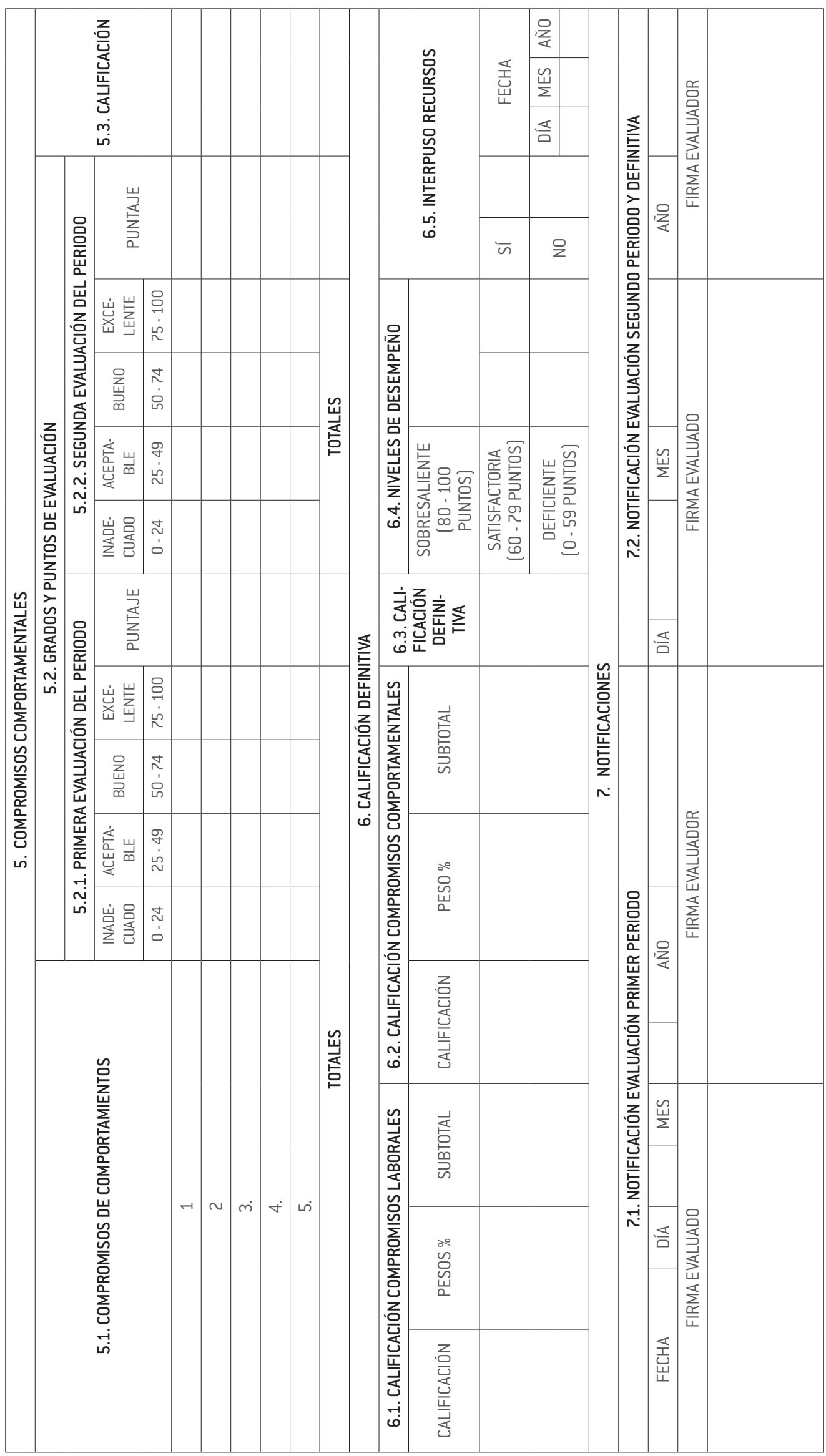

$\frac{0}{0}$
$\frac{0}{0}$
$\frac{0}{2}$
$\frac{1}{0}$
$\frac{0}{0}$
$\frac{\pi}{0}$
$\frac{0}{0}$
$\frac{0}{10}$
$\frac{10}{0}$
$\frac{8}{2}$ 
TABLA 8. Ejemplo cálculo de compromisos laborales

\begin{tabular}{|c|c|c|c|c|c|c|}
\hline \multicolumn{7}{|c|}{ 4. COMPROMISOS LABORALES } \\
\hline \multirow{2}{*}{$\begin{array}{l}\text { 4.1. COMPROMISOS ORIENTADOS AL } \\
\text { CUMPLIMIENTO DE LOS OBJETIVOS }\end{array}$} & \multirow{2}{*}{$\begin{array}{l}4.2 . \\
\text { EVIDENCIAS }\end{array}$} & \multicolumn{2}{|c|}{$\begin{array}{l}\text { 4.3. PRIMERA EVALUACIÓN } \\
\text { DEL PERIODO }\end{array}$} & \multicolumn{2}{|c|}{$\begin{array}{l}\text { 4.4. SEGUNDA EVALUACIÓN } \\
\text { DEL PERIODO }\end{array}$} & \multirow{2}{*}{$\begin{array}{l}4.5 . \\
\text { CALIFICACIÓN }\end{array}$} \\
\hline & & PUNTOS & $\begin{array}{c}\text { PESO } \\
\text { PORCENTUAL } \\
\text { ASIGNADO }\end{array}$ & PUNTOS & $\begin{array}{c}\text { PESO } \\
\text { PORCENTUAL } \\
\text { ASIGNADO }\end{array}$ & \\
\hline & & $1-100$ & $\%$ & $1-100$ & $\%$ & \\
\hline 1. & & 80 & $20 \%$ & 20 & $10 \%$ & 9 \\
\hline 2. & & 90 & $10 \%$ & 30 & $15 \%$ & $?$ \\
\hline 3. & & 70 & $15 \%$ & 45 & $20 \%$ & 10 \\
\hline 4. & & 50 & $30 \%$ & 60 & $30 \%$ & 17 \\
\hline 5. & & 100 & $25 \%$ & 70 & $25 \%$ & 21 \\
\hline 4.6. TOTALES & & & $100 \%$ & & $100 \%$ & 63 \\
\hline
\end{tabular}

Nota. Elaboración propia.

El resultado del objetivo 1 salió de la siguiente operación: $\left[\left(80^{*} 20 \%\right)+\left(20^{*} 10 \%\right)\right] / 2$, igual procedimiento para los demás objetivos pactados, la sumatoria de ello es de 63 punto para el ejemplo.

5. Compromisos comportamentales. Se deben registrar aquellos comportamientos que se desean del evaluado y que resulten clave en la eficacia y eficiencia del cargo desempeñado en congruencia con los valores, los principios y la cultura corporativa.

En la primera y segunda evaluación se registrará el puntaje en la columna que corresponde de inadecuado, aceptable, bueno y excelente. En la calificación se registra el promedio de los puntajes de la primera y segunda evaluación, dando como puntaje total la sumatoria de este promedio dividido en el número de objetivos comportamentales acordados.

6. Calificación definitiva. La calificación definitiva será la sumatoria de la calificación de compromisos laborales y la calificación de los compromisos comportamentales, en la calificación de los compromisos laborales se registra el puntaje resultante en la columna 4.5, el peso de la calificación es potestativo del evaluador de acuerdo con el interés de la empresa, igual procedimiento se realiza para la calificación de los compromisos comportamentales, dando como calificación el resultado de la celda 5.3. Se debe tener en cuenta que este peso porcentual y el dado en la calificación de compromisos laborales y comportamentales, debe ser igual al 100\%, en la parte del subtotal se registra la multiplicación de la calificación por el peso porcentual, igual procedimiento se hace con la calificación de los compromisos comportamentales. La calificación definitiva será la sumatoria de los subtotales de la calificación de compromisos laborales y comportamentales; en la parte de niveles de cumplimiento se registra el puntaje obtenido en la calificación definitiva, así, si es entre 80 y 100 puntos en la casilla de sobresaliente, entre 60 y 79 puntos en la casilla de satisfactoria y entre 29 y cero puntos en la casilla de deficiente; se anota si el evaluado interpuso recurso ante la calificación resultante y la fecha de presentación de esta.

7. Notificaciones. Se registran las fechas en las que se notifica la evaluación del primer periodo y segunda evaluación o definitiva, anotándose el día, mes y año, finalizando con las firmas de las partes involucradas. 


\section{Concertación DE OBJETIVOS}

Galpin (2013, p. 7) expresa que:

La falta de objetivos origina problemas. Sin objetivos claros, las personas normalmente harán una de las siguientes tres cosas: vagar sin metas durante la jornada de trabajo buscando tareas que les mantengan ocupados, correr alocadamente de una tarea a otra sin llegar a terminar ninguna, o esperar a que le asignen tareas y, una vez realizadas, volver a esperar una nueva asignación.

Por su parte, Alfaro Castellanos (2012, p. 43) manifiesta que:

Las organizaciones existen para propósitos diversos y por tanto, tienen varios tipos de objetivos organizacionales, económicos, de servicios y sociales.Un hospital por ejemplo, puede tener como propósito principal proporcionar asistencia médica de alta calidad a la comunidad. Por tanto, su objetivo principal se centra en proveer esta asistencia. Los objetivos organizacionales proporcionan a los administradores y a todos los demás miembros de la organización, importantes guías de acción en áreas como: toma de decisiones, planeación de personal, eficiencia organizacional, consistencia organizacional y evaluación del desempeño.

Cuando se fijan objetivos se deben tener en cuenta detalles tales como: los objetivos trazados deben mantenerse dentro de principios y valores de la empresa, si bien se deben indicar los resultados deseados, no se debe limitar la libertad para que el evaluado seleccione o escoja los métodos en los que desea hacerlo; los objetivos deben ser difíciles de alcanzar, pero tampoco al término de llegar a la imposibidad de realizarlos, Los objetivos debe ser congruentes con el periodo por evaluar, los objetivos deben ser específicos, en cuanto a los datos concretos: qué, cuánto, cuándo. Se deben centrar los objetivos en las labores por desarrollar, no en el hombre, se debe utilizar un lenguaje comprensible para el evaluado.

La concertación de objetivos es el primer contacto que se tiene de manera efectiva entre el evaluado y el evaluador, cuando se llega a esta etapa ya se deben tener definidos los siguientes aspectos: el tiempo en el que se debe desarrollar la evaluación, el instrumento con el que se va a evaluar y el método de evaluación por emplear, las funciones del cargos que desempeña el evaluado, debe existir la claridad por parte del evaluador de los objetivos laborales y comportamentales que deben cumplirse por parte del evaluado y la manera como se debe llevar a cabo una entrevista de concertación de objetivos.

En caso de que el método por utilizar implique la calificación de otros actores o stakeholders, se le debe hacer saber al evaluador en qué consiste esta evaluación complementaria y la incidencias que tendrá sobre la evaluación final.

\section{LA ENTREVISTA DE CONCERTACIÓN DE OBJETIVOS}

La entrevista de concertación de objetivos debe prepararse con anticipación, con el fin de que ambiente en el que ella se desarrolla propicie la retroalimentación pertinente por parte del evaluado, para que los objetivos concertados sean claros y precisos. Spakowsky (2021) aduce que:

La entrevista tiene como objetivo plantear algunos ejes temáticos sobre los que se desarrolla una conversación en la que los participantes opinan, comentan de manera libre e informal. En ocasiones la entrevista puede tener un guion preestablecido solo como una ayuda [de] memoria 
para orientar la conversación y no como algo que obture la misma. (p. 83)

Por otra parte, Werther y Davis (2008) señalan:

Las entrevistas directas con el personal a todo nivel constituyen una poderosa herramienta para obtener información sobre las actividades de recursos humanos e identificar áreas que necesitan mejorar. Por ejemplo, cuando se incrementa la tasa de rotación en la organización los especialistas del área de inmediato intentan identificar las causas que están conduciendo al problema. Las críticas y comentarios que se generan durante las entrevistas pueden ayudar a enterarse de las percepciones reales que existen respecto a determinado tema, y de esa manera ayudar a que la gerencia tome las acciones necesarias. (p. 501)

Para realizar la entrevista de concertación de objetivos, se sugiere:

- Preparar la entrevista. El evaluador debe tener a la mano instrumentos y documentos que le permitan documentar las razones de los objetivos por fijar; dentro de esta documentación se deben tener el plan estratégico de la empresa, el manual de funciones del cargo del evaluado, el manual de procesos y procedimientos, los estatutos de la empresa, el reglamento interno de trabajo, las anteriores evaluaciones del desempeño si existen, entre otros.

- Lugar de la entrevista. Preferiblemente, en el lugar de la entrevista de concertación de objetivos deben estar el evaluado y el evaluador, el lugar debe ser el apropiado para una conversación de confianza y fructífera, se debe determinar el tiempo en el que se llevará a cabo esta reunión.

- Desarrollo de la entrevista de concertación. En esta etapa se debe obtener información del evaluado y el evaluador con respecto a las directrices, orientaciones, comportamientos y visión de los que se desea conseguir en el periodo por evaluar.

- Terminación de la entrevista de concertación. La entrevista se terminará cuando el evaluador haya considerado que existe suficiente claridad sobre el futuro deseado con respecto a los compromisos laborales y comportamentales del evaluado, se terminará la entrevista formando un documento de concertación de objetivos, el cual se explicará más adelante.

\section{ESTÁNDARES OBJETIVOS}

El hecho de pedirle a los subordinados a evaluar que hagan su mayor esfuerzo para el éxito de la empresa no garantiza que esto se cumpla, Dessler (2009, p. 145) señala al respecto que:
Algunas descripciones de puestos con- tienen una sección de "estándares del desempeño", donde se establecen los es- tándares que debe alcanzar el empleado en cada una de las obligaciones y respon- sabilidades principales de la descripción del puesto. Nunca es fácil establecer es- tándares. Sin embargo, la mayoría de los gerentes aprenden muy pronto que el simple hecho de pedir a sus subordina- dos que "hagan su mejor esfuerzo" no es suficiente para garantizar un buen des- empeño.

Para establecer los objetivos, es necesario definir los estándares sobre los cuales se deben evaluar, un estándar para este caso será una medida referente sobre la cual se establecerán objetivos futuros de manera cuantificable. Koontz et al. (2012, p. 498) manifiestan que: "Cada meta de los muchos programas de planeación, cada actividad de estos programas, cada política, cada procedimiento y cada presupuesto pueden convertirse en un estándar 
respecto del cual podría medirse el desempeño real o esperado". Los estándares, según este autor, pueden ser: físicos, de costos, de capital, de ingresos, de programas, intangibles, de metas y los planes estratégicos como puntos para el control estratégico.

\section{PLANEACIÓN ESTRATÉGICA}

Dussan-Pulecio y Serna-Gómez (2017, p. 23) definen la planeación estratégica como:

Un proceso sistemático que permite a quienes deben tomar decisiones en la unidad empresarial obtener, procesar y analizar información endógena y exógena para utilizarla en la toma de decisiones que mantengan la empresa competitiva y proyectada hacia el futuro.

González Millan (2020, p. 10), desde su crítica, expresa que:

La planeación estratégica se ha convertido en una herramienta de indiscutible aplicación para la gestión gerencia moderna, pues a pesar de sus antecedentes neoclásicos aun hoy se constituye en un elemento clave que se viene aplicando sistemáticamente en pro del desarrollo empresarial.

Con la planeación se fijan los objetivos futuros por cumplir para llegar a la visión empresarial. Necesariamente, a esos objetivos se les debe asignar responsables y esta responsabilidad debe ser evaluada, por esta razón es importante que se tengan en cuenta los objetivos diseñados en la planeación estratégica al momento de fijar los objetivos laborales de los evaluados.

\section{ANÁLISIS Y DESCRIPCIÓN DE CARGOS}

Zuluaga Giraldo (2007, p. 65) afirma que:
La descripción de cargos se ocupa de las funciones, responsabilidades y actividades que en general allí se desarrollan, es decir los aspectos intrínsecos; el análisis de puestos de trabajo se ocupa de identificar las características y requisitos que se exigen para ocupar dicho cargo, es decir los aspectos extrínsecos. Estos dos van a permitir identificar con mayor claridad el perfil del candidato que podría ocupar dicho cargo.

En el aparte de la descripción del cargo, se encuentran la naturaleza y las funciones del cargo; en el análisis encontramos las competencias que deben tener las personas que desempeñan el cargo. Por estas razones, se sugiere tener en cuenta estos aspectos en el momento de fijar los objetivos entre el evaluado y el evaluador, para no caer en errores de fijar objetivos que no estén en el marco de las funciones del cargo o que el evaluado no cuente con las competencias para cumplir con el o los objetivos fijados.

\section{COMPROMISOS LABORALES}

Cuahonte Bandillo (2019, p. 10) aduce a que:

La competencia comporta todo un conjunto de conocimientos, procedimientos y actitudes combinadas, coordinados e integrados, en el sentido que el individuo a de "saber hacer" y "saber estar" para el ejercicio profesional. El dominio de estos saberes le hacen "capaz de" actuar con eficacia en situaciones profesionales.

Los compromisos laborales son aquellos que tienen una relación directa con la labor, la tarea o las funciones que desarrolla el evaluado, estos compromisos laborales están plasmados en la descripción y el análisis de cargos y tienen una relación directa con los objetivos del plan estratégico, como ya se había manifestado. 


\section{COMPROMISOS COMPORTAMENTALES}

Newstrom (2011, p. 6) indica que:

Una de las grandes fortalezas del comportamiento organizacional es su naturaleza interdisciplinaria, que integra las ciencias de la conducta (cuerpo sistemático de conocimiento que se refiere a por qué y cómo las personas se conducen como lo hacen) con otras ciencias sociales que contribuyen a esta materia. De estas disciplinas aplica cualquier idea que mejore las relaciones entre la gente y las organizaciones. Su naturaleza interdisciplinaria es similar a la de la medicina, que aplica conocimientos de las ciencias físicas, biológicas y sociales en una práctica médica factible.

Si los compromisos laborales tienen relación con el análisis y la descripción del cargo, así como con la planeación estratégica de la empresa, los compromisos de comportamiento tienen que ver con la conducta deseada de los evaluados, según los valores y la cultura empresarial, el evaluador debe tener en cuenta esos comportamientos deseados para evaluarlos y adoctrinar al evaluado en su cumplimiento, por cuanto ello identifica la personalidad de toda empresa.

Dentro de estos comportamientos, podemos destacar: el interés de capacitación del evaluado, la forma como atiende a los usuario o clientes, el compromiso con la empresa, trabajo en equipo, adaptación al cambio, visión, liderazgo, planeación, toma de decisiones, pensamiento holístico, resolución de conflictos, creatividad e innovación, iniciativa, relaciones interpersonales, conocimientos generales, disciplina, responsabilidad, calidad en la entrega de trabajos, manejo de la información, colaboración, etcétera.

\section{INSTRUCTIVO PARA LA CONCERTACIÓN DE} OBJETIVOS LABORALES

En la tabla 9, se presenta un modelo o formato para diligenciar en la concertación de objetivos entre el evaluado y el evaluador. En este instrumento se deben registrar los datos básicos del evaluado y el evaluador, como sus nombres y apellidos, documentos de identidad, cargos y la dependencia donde laboran; asimismo, se registran los objetivos de la planeación estratégica que tienen una relación directa con el cargo ocupado por el evaluado, el periodo que se evaluará, los compromisos laborales pactados, las evidencias por tener en cuenta en la evaluación y los porcentajes de pesos que tendrán cada uno de los objetivos laborales por evaluar. Para esto último se debe tener en cuenta que la sumatoria de los porcentajes dados a los objetivos, tanto en la primera como en la segunda evaluación, no deben ser igual al 100\%, y el peso porcentual que tendrán estos objetivos en la evaluación final.

Para finalizar la evaluación se fijan los objetivos de comportamiento y las evidencias que se tendrán en cuenta para evaluarlos, así como el peso que estos objetivos tendrán en la evaluación final; se debe tener la precaución que la sumatoria de peso porcentual de los objetivos laborales y comportamentales deben ser iguales al 100\%. Este documento debe ser firmado por el evaluado y el evaluador en la fecha en que se concertaron los objetivos, que debe ser por los menos dentro de los diez días del periodo de la evaluación del desempeño.

\section{EL SEGUIMIENTO AL EVALUADO}

Es necesario que el evaluador realice seguimiento a los objetivos y los compromisos pactados con el evaluado; para ello, es recomendable 
que lleve a manera de bitácora un instrumento que le sirva para registrar las novedades que presenta el evaluado durante el periodo que se va a evaluar.

En la tabla 10 se presenta un formato o instrumento que puede llevar el evaluador para ir registrando estas novedades; en este se registran los datos inicialmente registrados en el formato de concertación de objetivos, como los son los datos básicos del evaluado y el evaluador, así como los motivos de los registros realizados y si estos se tratan de compromisos de tipo laboral o de comportamiento y la fecha en la que ello ocurrió, firmando las partes como constancia de lo ocurrido. Es de anotar que sirven de evidencias los sucesos en los que se resalta el desempeño del evaluado, como aquellos en los cuales se han evidenciado errores.

TABLA 9. Formato de concertación de objetivos

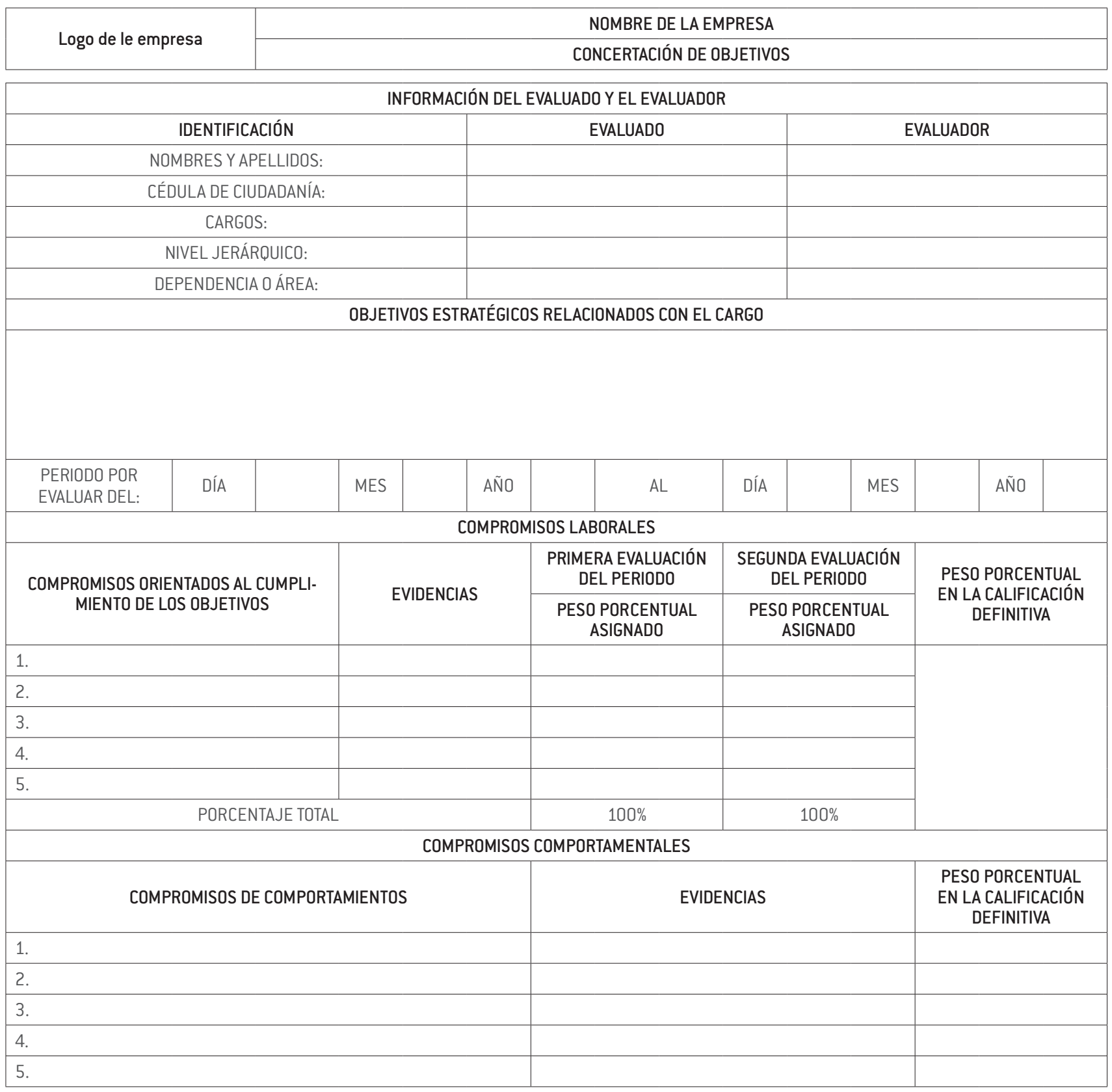




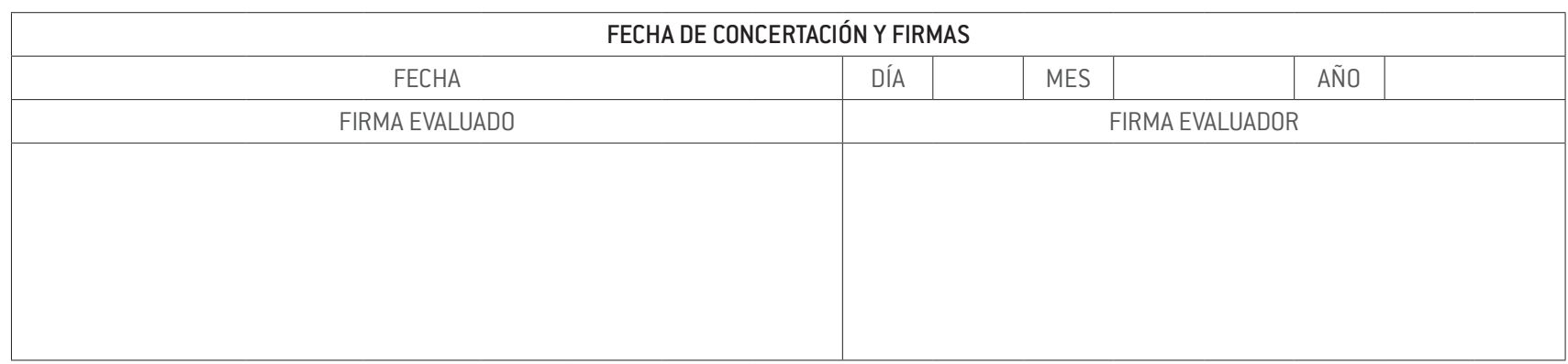

Nota. Elaboración propia.

TABLA 10. Formato de registro de evidencias

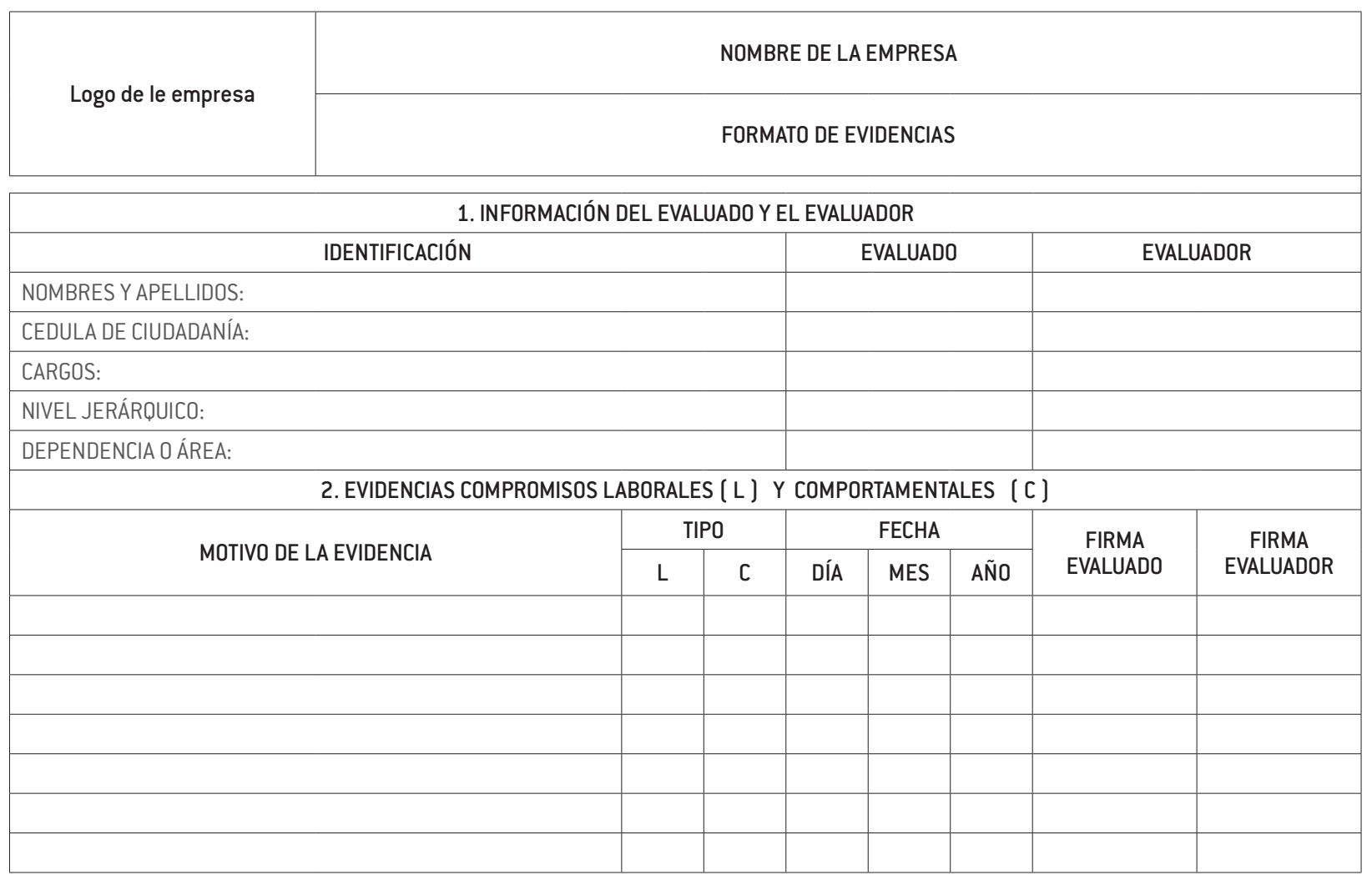

Nota. Elaboración propia.

COMPARACIÓN DE

\section{RESULTADOS VS LOS OBJETIVOS CONCERTADOS}

Valadez Treviño (2020, p. 116) manifiesta que:

Los resultados derivados de la evaluación de desempeño, para efecto de determinar los logros, es indispensable contar con un punto de comparación, a fin de determinar los avances o retrocesos encontrados, al mostrar tanto el estado inicial como el actual de la problemática y, de esta manera, darles el verdadero valor e importancia a los resultados mediante indicadores.

Los indicadores constituyen una herramienta de importancia al momento de fijar los 
objetivos. Al respecto, Mora García (2008, p. 17) señala:

Los indicadores de gestión se convierten en los signos vitales de la organización, y su continuo monitoreo permite establecer las condiciones e identificar los diversos síntomas que se derivan del desarrollo normal de las actividades; en una organización también se debe contar con el mínimo número posible de indicadores que nos garanticen contar con información constante, real y precisa sobre aspectos tales como: efectividad, eficiencia, eficacia, productividad, calidad, la ejecución presupuestal, la incidencia de la gestión todos los cuales constituyen el conjunto de signos vitales de la organización.

Es común que los indicadores se elaboren en forma de fraccionario, que a manera de división registra en el numerador los logros alcanzados y en el denominador lo planeado o pactado que se va a llevar a cabo.

\section{FiJACIÓN DE ACCIONES}

\section{CORRECTIVAS}

Un concepto acertado y completo acerca de las acciones correctivas en los sistemas de evaluación del desempeño laboral pertenece al aporte de McGregor (2006, p. 136), quien manifiesta que:

La mayoría de las personas necesitan y desean retroalimentación con respecto a su desempeño. Esto a su vez permite que ambos desarrollen un plan para corregir cualquier deficiencia que la evaluación haya descubierto y les permita reforzar las cosas que el subordinado hace correctamente. Finalmente, la evaluación puede y debe ser central en el proceso de planeación de carrera en la empresa ya que ofrece una buena oportunidad para revisar los planes de carrera de la persona a la luz de sus fortalezas y debilidades demostradas.

Lo ideal en toda evaluación del desempeño es corregirlos antes de llegar a su incumplimiento y cuando ya no existe el tiempo para reorientar el camino y hacer que los objetivos lleguen a su feliz término; en tal virtud se recomienda que las evaluaciones del desempeño se revisen en periodos prudenciales y de acuerdo con la necesidad y la importancia del objetivo, con el fin de tomar las acciones correctivas para que estos se cumplan.

\section{EVALUACIÓN FINAL}

En esta etapa, el evaluado y el evaluador deben reunirse para efectos de analizar el cumplimiento de los objetivos pactados, se debe diligenciar el instrumento para evaluar el desempeño en las empresas del sector privado (figura 6), dejar constancia en este de la notificación de la calificación, señalándose la fecha en que esta se efectúa.

La evaluación final debe manejarse con objetividad. En esta etapa, se deben evitar errores en la evaluación como: resaltar los acontecimientos recientes, dejando a un lado el comportamiento sobresaliente que ha tenido el evaluado durante el periodo por evaluar; en ocasiones, el evaluador se forma opiniones y percepciones por el estereotipo del evaluador, que pueden incidir en la objetividad de la evaluación, porque el evaluado sea una persona gorda o delgada, blanca, negra o de cualquier otra raza, de alguna religión, de algún movimiento político o social, etcétera; caer en el error de evaluar con tendencia a promedios centrales, en cuanto a considerar al evaluado ni bueno ni malo; evaluar por la simpatía o antipatía que se siente hacia el evaluado; evaluar para obtener popularidad o afecto de las personas por evaluar; el evaluador ponerse en la 
posición de que los evaluados se parezcan a el o ella y que actúen en esa dirección, etcétera.

La evaluación final debe contener unos niveles de desempeño, los cuales varían de una empresa a otra. En la tabla 11 se propone una escala de cumplimiento de los objetivos dentro del marco del instrumento y método de evaluación propuesto.

TABLA 11. Niveles de desempeño

\begin{tabular}{|c|c|}
\hline NIVELES DE DESEMPEÑO & PORCENTAJE \\
\hline SOBRESALIENTE & ENTRE 80 y 100 \\
\hline SATISFACTORIO & ENTRE 60 y 79 \\
\hline DEFICIENTE & ENTRE 0 y 59 \\
\hline
\end{tabular}

Nota. Elaboración propia.

Con estos parámetros dados de desempeño, aquellos evaluados que obtengan una evaluación entre el 80\% y 100\% tendrán un desempeño sobresaliente; entre el $60 \%$ y $79 \%$ satisfactorio; y entre 0\% y 59\% deficiente. Estos parámetros servirán para tomar decisiones de incentivos y retiro del servicio de los evaluados.

Por último, se debe hacer una retroalimentación para que tanto el evaluado como el evaluador analicen las debilidades y las fortalezas que pudieron darse durante la evaluación del desempeño, con el fin de evitar en próximas evaluaciones los errores cometidos y reforzar aquellos aspectos que sirvieron para el cumplimiento de los objetivos.

\section{RECURSOS POR INTERPONER EN}

\section{LA EVALUACIÓN}

En la Constitución Política de Colombia se establece en el artículo 29 que: "El debido proceso se aplicará a toda clase de actuaciones judiciales y administrativas" (Congreso de la República de Colombia, 2021, p. 6). Asimismo, el Código Contencioso Administrativo, contenido en la Ley 1437 del 2011, cuyo ámbito de aplicación es válido para los particulares, cuando cumplen funciones administrativas, como se consagra en el artículo segundo, establece también en el articulo 74 que contra los recursos administrativos proceden los recursos de reposición y apelación (Congreso de la República de Colombia, 2021).

Es recomendable entonces que ante una decisión que se tome con respecto a la evaluación del desempeño, se le dé la oportunidad al evaluado de interponer los recursos de reposición ante su superior inmediato y de apelación ante la instancia superior del evaluador, todo lo anterior buscando la objetividad en la evaluación.

Estos recursos los puede interponer el evaluado dentro de los cinco días siguientes a la notificación de la evaluación. En los recursos interpuestos se darán los motivos de la inconformidad de la calificación otorgada, el superior inmediato se podrá sostener en la evaluación o en su defecto sostenerla, dando sus argumentos. Superado este proceso, la administración tomará una decisión sobre el retiro del evaluado ante una evaluación deficiente.

\section{Apartado final}

A manera de conclusión, se puede decir que:

1. La evaluación del desempeño es una herramienta que sirve para lograr el cumplimiento de los objetivos laborales y comportamentales de las empresas; con ello se aseguran las metas y el futuro o visión deseado.

2. Las estrategias para evaluar el desempeño no solo deben ser una labor del área de personal, sino también de todas aquellas que, de una u otra manera, tienen la responsabilidad en el cumplimiento de los objetivos estratégicos. 
3. La responsabilidad de la evaluación del desempeño debe recaer inicialmente sobre el jefe inmediato, sin embargo, si el evaluado tiene relaciones con clientes internos y externos que son fundamentales en el cumplimiento de los objetivos, se puede contemplar la posibilidad que estos intervengan en la evaluación, con el fin de comprometer al evaluado con el desempeño laboral de todos los actores que tengan que ver con las funciones del cargo que desempeña.

4. El periodo en que se debe evaluar el desempeño laboral depende de la importancia que tienen los objetivos en la misión y visión corporativa, sin embargo, se recomienda que cuando el periodo por evaluar sea igual o mayor a un año, se realice seguimiento a mitad de periodo para corregir las desviaciones que se puedan presentar.

5. La evaluación del desempeño es un proceso que debe planearse y educarse; en este proceso se deben definir aspectos como el instrumento y el método por utilizar, el periodo por evaluar, los objetivos de la evaluación del desempeño, etcétera.

6. La concertación de los objetivos lleva a que se entrevisten evaluado y evaluador, y en ella se deben diseñar los objetivos por cumplir por parte del evaluado.

7. La planeación estratégica, el análisis y la descripción de cargos son herramientas que les sirven al evaluador para fijar los objetivos laborales, ya que con ello se asegura en gran parte el cumplimiento de la visión corporativa.

8. Los objetivos comportamentales, tienen relación con los valores, los principios y los valores corporativos, con ellos se trata se asegurar que el comportamiento del evaluado corresponda al deseado por la empresa, según la personalidad y la cultura en ella deseada.

9. Los objetivos que se establezcan con el evaluado, si bien no deben ser fáciles de conseguir, tampoco llegar al término de que sea imposible su logro.

10. En la evaluación final se deben evitar los errores propios de una evaluación cargada de subjetividad, lo anterior contrasta con el fin de la evaluación del desempeño, como lo debe ser el cumplimiento de los objetivos laborales y comportamentales del evaluado.

\section{TALLER}

En equipos de dos integrantes en los cuales uno debe hacer de evaluado y otro de evaluador, escoja una empresa donde se conozca la planeación estratégica, el análisis y la descripción de cargos y los valores corporativos. Con la anterior información deben:

1. Seleccionar un cargo que se supone es el que ocupa el evaluado en el equipo conformado.

2. Concertar los objetivos laborales por cumplir durante el periodo de un año, del 1 de enero y 31 de diciembre. Para lo anterior tome cinco objetivos laborales que tengan relación con la planeación estratégica institucional y las funciones descritas en el análisis y la descripción del cargo escogido y establezca los porcentajes asignados a cada uno de ellos de acuerdo con su importancia en cada uno de los seguimientos.

3. Concertar los objetivos comportamentales por cumplir durante un año, para lo anterior tenga en cuenta los valores y los principios corporativos. 
4. Con los anteriores datos, diligencie el formato ilustrado en la figura 11.

5. El evaluador supone que en el primer seguimiento el evaluado presentó novedades desfavorables en el desempeño de los objetivos 1 y 3 de los compromisos laborales, que conlleva a disminuirle la evaluación en un 30\% y 40\% del porcentaje dado; igualmente estuvo aceptable en los objetivos comportamentales 2 y 5 .

6. En el segundo y último seguimiento, el evaluado presentó novedades desfavorables en el desempeño de los objetivos 2 y 4 de los compromisos laborales, lo que conlleva a disminuirle la evaluación en un 10\% y 5\% del porcentaje dado; igualmente, estuvo inadecuado en los objetivos comportamentales 3 y 4.

7. Con las novedades de los puntos 5 y 6 , diligencie el formato de registro de evidencias, identificado con la figura 12.

8. Finalmente, realice la evaluación final diligenciando el formato Instrumento para evaluar el desempeño en las empresas del sector privado, de la figura 6 .

\section{PREGUNTAS DE REPASO}

1. ¿Definir qué es la evaluación del desempeño laboral?

2. ¿Cuál es el proceso para llevar a cabo una evaluación de desempeño laboral?

3. ¿Qué instrumento y método se pueden aplicar en una evaluación del desempeño laboral y cuál es la ventaja y desventaja de cada uno de ellos?

4. ¿Cuál es el tiempo adecuado para realizar una evaluación del desempeño laboral y por qué?

5. ¿Cómo se deben concertar objetivos en una evaluación del desempeño laboral?

6. ¿Cómo se debe hacer el seguimiento a los objetivos en una evaluación del desempeño laboral?

7. ¿Por qué se deben corregir las desviaciones en el cumplimiento de los objetivos laborales?

8. ¿Qué recursos puede tener el evaluado ante una evaluación del desempeño laboral deficiente?

\section{REFERENCIAS}

Alfaro Castellanos, M. (2012). Administración de personal. Red tercer milenio.

Alles, M. (2010). Desempeño por competencias: evaluación de 360. Ediciones Granica. https://bbibliograficas.ucc. edu.co:2280/es/ereader/ucc/66695? page=149.

Alles, M. A. (2008). Desempeños por competencias, Ev de 360 grados. Granicia.

Asamblea Nacional Constituyente. (6 de julio de 1991). https://www.corteconstitucional.gov.co.

Bonnefoy, J. y Armijo, M. (2005). Indicadores de desempeño en el sector público. Cepal.

Castillo Aponte, J. (2008). Administración de personal: un enfoque hacia la calidad. Ecoe Ediciones.

Chiavenato, I. (2017). Administración de recursos humanos: El capital humano en las organizaciones. McGraw-Hill.

Comisión Nacional del Servicio Civil. (22 de Enero de 2008). Función pública, https://www.funcionpublica.gov.co Comisión Nacional del Servicio Civil. (10 de octubre de 2018). Normatividad y acuerdos. https://www.cnsc. gov.co 
Congreso de la República de Colombia. (23 de septiembre de 2004). Ley 0909 del 2004. http://www.secretariasenado.gov.co/senado/basedoc/ley_0909_2004.html

Congreso de la República de Colombia. Ley 1437 de 2011. Consultado el 4 de agosto del 2021. http://wsp.presidencia.gov.co/Normativa/Leyes/Documents/ley143718012011.pdf

Congreso de la República de Colombia. Constitución Política de Colombia. Consultado el 4 de agosto del 2021. https://dapre.presidencia.gov.co/normativa/normativa/Constitucion-Politica-Colombia-1991.pdf

Cuahonte Bandillo, L. (2019). Manual para la Evaluación Formativa de las Competencias. Ediciones CCAT.

Dessler, G. (2015). Administración de recursos humanos. Pearson Educación.

Dussan-Pulecio, C. y Serna-Gómez, H. (2017). Planeación estratégica para Mipymes. Universidad Cooperativa de Colombia. doi:https://doi.org/10.16925/greylit.2085

Flores Mendoza, R. y Cervantes Penagos, M. (2019). Evaluación del desempeño del Gobierno Corporativo. Instituto Mexicano de contadores públicos.

Galpin, T. (2013). Medir el desempeño. Diaz de santos.

González Millán, J. J. (2020). Manual práctico de planeación estratégica: Edición Días de Santos.

Koontz, H., Weihrich, H. y Cannice, M. (2012). Administración una perspectiva global y empresarial. McGraw-Hill.

Lévy Leboyer, C. y Prieto, J. (2001). Gestión de las competencias: cómo analizarlas, cómo evaluarla, como desarrollarlas.

Ediciones Gestión.

López Carrillo, J. M. (2013). Análisis comparativo de evaluación de desempeño. Repositorio institucional UASB-DIGITAL.

Martínez, F. G. (2012). La evauación del rendimiento. Díaz de santos.

McGregor, D. (2006). El lado humano de las empresas. McGraw Hill Interamericana.

Mejía-Herrera, E. (julio del 2019). Generalidades de planeación. Ediciones Universidad Cooperativa de Colombia. https://doi.org/10.16925/gcnc.06

Mora García , L. A. (2008). Indicadores de la Gestión Logística. Ecoe Ediciones.

Newstrom, J. W. (2011). Comportamiento humano en el trabajo. Mc Graw Hill.

R. Wayne Mondy, S. (2010). Administración de recursos humanos. Prentice Hall.

Spakowsky, E. (2021). La Evaluación Institucional. Homo Sapiens Ediciones.

Valadez Treviño, F. J. (2020). Evaluación del desempeño: Herramienta para la validación fiscal de erogación estrictamente indispensable. Instituto Mexicano de Contadores Públicos.

Werther, W. B. y Davis, K. (2008). Administración de recursos humanos: el capital humano de las empresas sexta edición. Mc Graw Hill.

Wether, W. B. y Davis, K. (2004). Administración de personal y recurso humano. McGraw-Hill.

Zuluaga Giraldo, R. (2007). Creación y consolidación de empresas. Ecoe ediciones. 


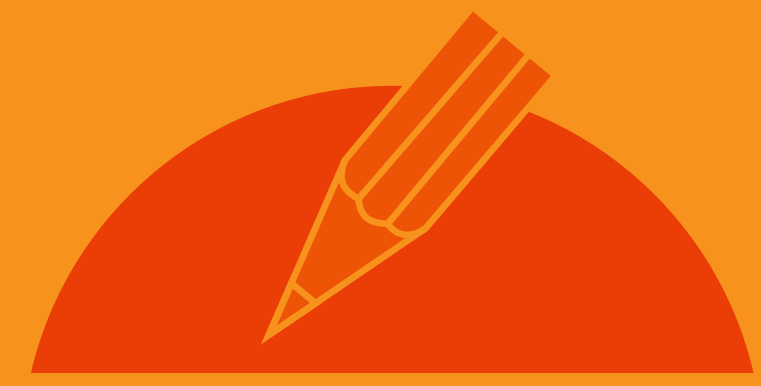

Notas

de clase 